Part of Journal of Research of the National Bureau of Standards, Volume 21, October 1938

\title{
A DETERMINATION OF THE ABSOLUTE OHM, USING AN IMPROVED SELF INDUCTOR
}

\author{
By Harvey L. Curtis, Charles Moon, and C. Matilda Sparks
}

\section{ABSTRACT}

A second determination of the value of the absolute ohm has been completed. The same method as that previously described has been followed. This required the computation of the inductance of a solenoid from its measured dimensions and the electical measurement of the same inductance in terms of resistance and time. Refinements were made in many of the details of measurement. Two important improvements were introduced. A new inductor was constructed in which the wire was wound in a screw thread of uniform pitch cut in a glass tube. The error in the computed inductance which resulted from the variations in pitch has been practically eliminated, whereas in the previous inductors this introduced one of the largest uncertainties. The other improvement was in the alternatingcurrent bridge measurements, where the effect of the capacitance to earth of the inductor was evaluated.

The result of this determination is

\section{$1 \mathrm{NBS}$ international ohm $=1.000479$ absolute ohms.}

By estimating the capacitances to earth of the inductors used in the previous work, corrections have been applied to the results there obtained. The weighted average of this result and the corrected results from the previous publication is

\section{NBS international ohm $=1.000468$ absolute ohms.}

The authors are of the opinion that this weighted average differs from the true value by less than 20 parts in a million.

\section{CONTENTS}

I. Introduction

II. Construction of a self inductor with uniform pitch

1. Rough grinding of the form for the inductor.

2. Grinding and lapping of the thread on the form
3. Measurements for uniformity of pitch and diameter of the form

4. Lapping to produce uniform diameter

5. Drawing the wire and winding it on the form

6. Polishing spots on the wire and making rulings on them

III. Measurement of the dimensions of the inductor.

1. Pitch of the winding

(a) Micrometer method.

(1) Length standards

(2) The headstock

(3) The tailstock.

(4) Computation of the pitch 
III. Measurement of the dimensions of the inductor-Continued.

1. Pitch of the winding--Continued.

(1) Micrometer microscopes

(2) Methods of illuminating the scale.... 387

a. Bright-field illuminator......... 387

b. Dark-field illuminator _.......... 387

c. Comparison of the two illuminators -- 388

(3) Readings on the lines ruled on the wires_ 388

(4) Mounting for the standard scale........ 389

2. Outside diameter of the helix . .

(a) The micrometer . .

(b) Length standards......... 390

3. Diameter of the wire

IV. Observational data and results on the mechanical dimensions of the helix.

1. Pitch of the helix

(a) Uniformity of the pitch of the helical thread.....

(b) Expansivity from measurements of pitch before winding-

(c) Pitch after winding

(1) Micrometer method

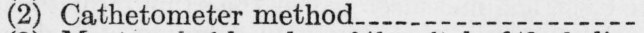

(3) Most probable value of the pitch of the helix.

(4) Increase in the pitch produced by the winding -

2. Outside diameter of the helix

3. Circularity of cross sections of the solenoid.

4. Diameter of the wire

(a) Diameter of the wire by the micrometer method..-

(b) Diameter of the wire from the length, mass, and density.

V. Computation of the inductances.

1. Inductance of the helix

2. Inductance of the leads

3. Inductance of the substitution inductor ......... 406

4. Effect of permeability of the form

5. Computed inductance difference

VI. Measurement of the inductance in NBS international electrical

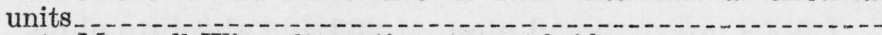

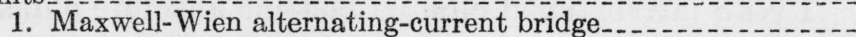

(a) Bridge resistors._.

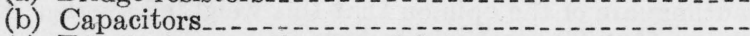

(c) Effect of magnetic material

(d) Special switches

(e) Capacitance to earth of the solenoid ..........

2. Maxwell capacitance bridge

(a) The vibration commutators .....

(b) The galvanometers

(c) The bridge

(d) The calibrating resistors

(e) The resistance of the battery

$\mathrm{X}$. Weighted result of this and the previous investigation

\section{INTRODUCTION}

An investigation to determine the value of the absolute ohm has been in progress at the National Bureau of Standards for more than a decade. This paper describes the developments in apparatus that have occurred since the previous publication ${ }^{1}$ and records the results that have been obtained by the use of the improved equipment.

1 Curtis, Moon, and Sparks, An absolute determination of the ohm. J. Research NBS 16, 1 (1936) RP857. Throughout the present paper references to the "previous paper," "the previous article," etc., refer to that publication. 
The underlying principle employed in these determinations is that the ratio of the absolute ohm to the international ohm is the same as the ratio of the absolute henry to the international henry. The experimental procedure consisted first in determining the value of an inductance in absolute henrys from the measured dimensions of an inductor and from the permeability of the surrounding medium. The value of the same inductance in international henrys was then determined from electrical measurements which depended only on the international ohm and the mean solar second. The ratio of the two values of the inductance permits the determination of the values of resistance standards in absolute ohms from their values in international ohms.

The present description will omit many details that were given in the previous paper. An effort has been made to have the present paper sufficiently complete so that the reader can understand the purpose of all the improvements, but it will be necessary to refer to the previous article for the description of those things that have not been appreciably changed.

In the previous publication it is shown that the greatest uncertainties in the final result arose from the variations in the pitch of the helix and the possibility that the galvanometers which were used in the absolute measurement of capacitance did not correctly integrate the current. Special consideration has been given to the elimination of these uncertainties. The apparatus designed for this purpose will be described in detail. At the same time, many things of lesser importance were improved and will be reported.

\section{CONSTRUCTION OF A SELF INDUCTOR WITH UNIFORM PITCH}

A new self inductor was constructed. This was a single-layer solenoid in which the pitch of the winding was more uniform than in any of the solenoids previously described. This was accomplished by winding the wire of the solenoid in a uniform screw thread that was ground and lapped in a cylindrical tube which served as the form of the inductor. With this type of construction there is greater difficulty in obtaining a uniform diameter than with a plain cylinder, such as was used previously. All of the processes of construction will be described in detail.

\section{ROUGH GRINDING OF THE FORM FOR THE INDUCTOR}

The form for the inductor was of Pyrex glass. As received from the manufacturer, the tube was annealed and the ends ground flat and polished, but the inside and outside surfaces were unfinished. The polished ends permitted an examination of the form for bubbles in the glass. These bubbles were very numerous, but of those near the outside surface the largest had a diameter of less than $4 \mathrm{~mm}$. The form was about $120 \mathrm{~cm}$ long, from 36 to $37.5 \mathrm{~cm}$ in outside diameter, and its wall thickness was about $10 \mathrm{~cm}$. Conventional methods were used to rough-grind the outside and inside surfaces, so that they were nearly cylindrical and gave an approximately uniform wall thickness to the form. Then the method described in the previous paper for 
grinding and lapping the outer surface to a very true cylinder was used, but this operation was continued only until the variations in diameter were reduced to $0.005 \mathrm{~mm}$.

\section{GRINDING AND LAPPING OF THE THREAD ON THE FORM}

The form was then mounted in a screw-cutting lathe by clamping it between end plates that fitted on a 2 -inch mandrel. A shallow spiral groove was cut into the form by means of a steel disk, the rim of which was charged with diamond dust. The disk was mounted in bearings on the lathe carriage and was run at a speed of about $7000 \mathrm{rpm}$ by a belt-connected motor. The disk was enclosed in a housing which was partially filled with kerosene. The form, at the point where it was being cut by the disk, was kept continually wet with kerosene which dripped from an overhead supply. The glass form was rotated at a rate of about 1 revolution in 2 minutes so that 40 hours were required to cut the thread. The groove had only sufficient depth to guide the lapping tool which was later used to shape the thread.

The form was then removed from the lathe and mounted on a shaft by means of a pneumatic device. This device consisted of a wooden cylinder wound with rubber tubing. The cylinder, which was about a meter long and $20 \mathrm{~cm}$ in diameter, had a hole along its axis through which the shaft passed. The cylinder was fastened to the shaft. The shaft and pneumatic device were inserted in the glass form when the rubber tube was collapsed by applying a vacuum. The rubber tubing was then inflated to about $1 / 2$ of an atmosphere above normal atmospheric pressure. In this way the glass form was supported uniformly throughout its length. This mounting did not accurately aline the axis of the tube with that of the shaft, but this alinement was not necessary for the method of lapping which was employed.

Two laps were used to grind the groove; a long lap for obtaining uniformity of pitch with only slight variations in diameter, and a short lap for removing variations in diameter. The laps are shown in figure 1. The framework of the long lap was made of four Pyrex-glass tubes, each about $4 \mathrm{~cm}$ in diameter and $75 \mathrm{~cm}$ long, which were held in an iron frame and on which were mounted wrought-iron blocks having threads of the same pitch as those on the glass form. The blocks were portions of a wrought-iron pipe that had about the same inside diameter as the outside diameter of the threaded glass form. A 7 -cm length of the wrought-iron pipe was threaded on the inside in the same lathe that was used in cutting the thread on the outside of the glass form. This length was then cut into 32 segments which constituted the blocks used in making the lap. The blocks were assembled in four rows on the threaded glass form with their threads meshing into those of the form and with each row underneath a glass tube of the lap. Beeswax was used to hold the blocks to the glass tubes of the lap. This lap, which was long and light, had the same over-all coefficient of expansion as the form to be lapped, and the same average pitch, but the shape of the threads was quite different on the lap from those on the glass tube. This is shown by the profiles $A$ and $B$ of figure 2. The lapping process consisted in grinding the surface of the lap to fit the surface of the form, using a suspension of emery in water as a grinding material. The procedure was to coat the tube with the emery suspension, to place the lap on one end of the 


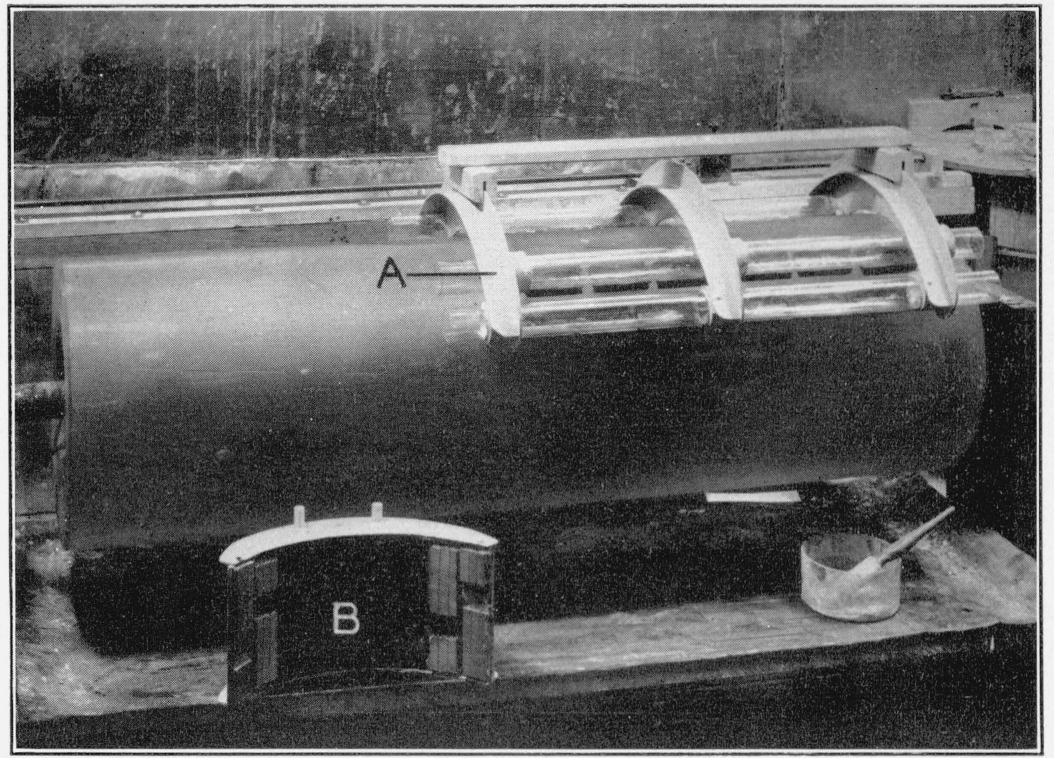

FiguRE 1.-Laps used in fashioning the threads on the long glass form.

The long lap, $A$, rests on the glass form so that the lapping surface cannot be seen. Pyrex-glass tubes are used as the longitudinal elements of the lap. The short lap, $B$, has a frame of wrought-iron plates. Both laps were constructed to have as great rigidity as possible.

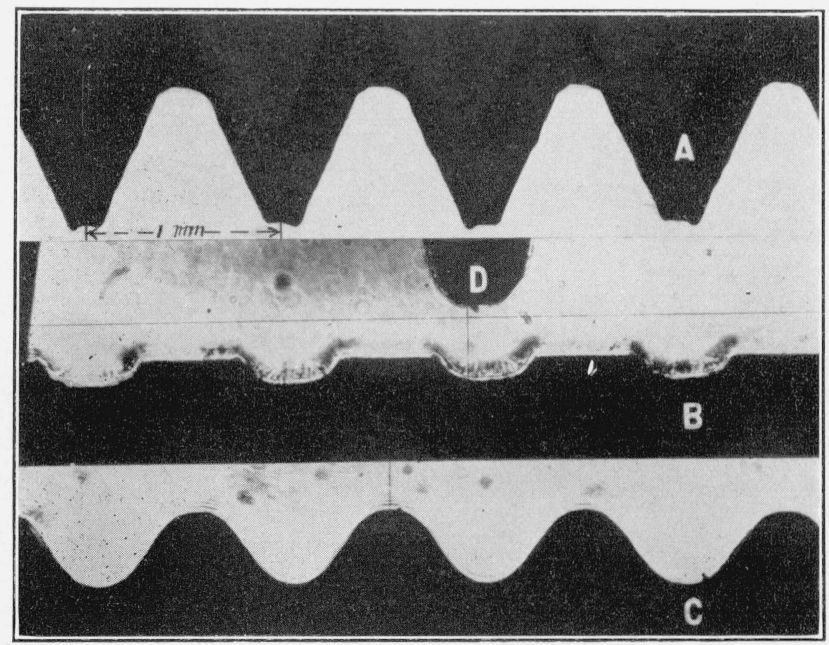

FIGURE 2.-Enlarged photographs showing, in silhouette, the steps in the production of the thread on the glass form.

$A$ is the profile of the original thread on the lapping tool; $B$ is the profile of the original thread ground in the glass by means of the diamond-charged steel wheel.

During the lapping process both the lapping tool and the glass wore away until the two fitted together with

the profile, as shown at $C$, which is the finished thread on the glass form.

The edge of the grinding wheel is shown at $D$. 


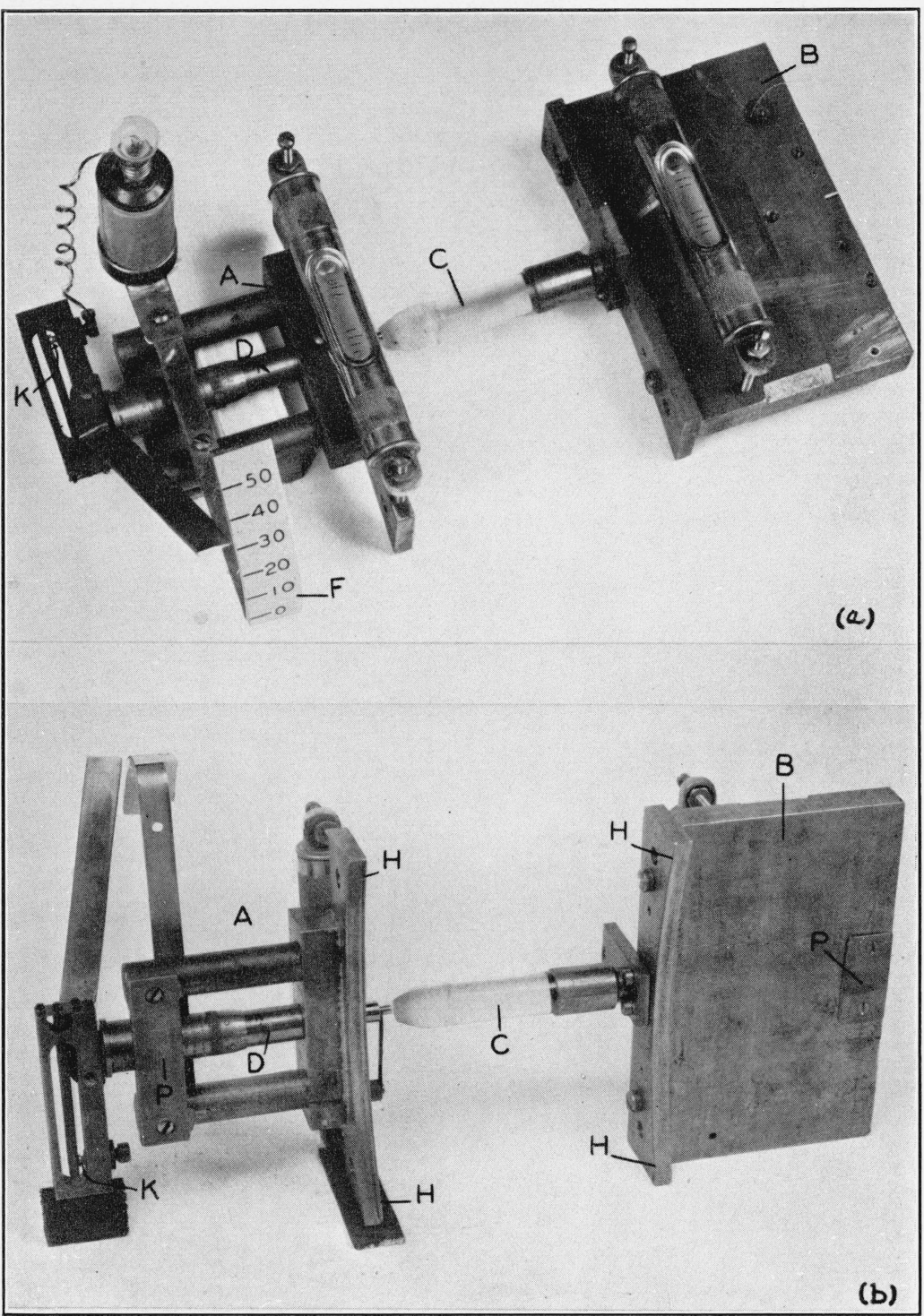

FIgure 3.-Micrometer used in determining the uniformity of pitch of the form (a) top view, (b) bottom view.

The headstock is designated as $A$, the tailstock as $B$. By means of the sensitive levels the headstock and tailstock can be placed in the same position relative to each other regardless of their positions on the form. The length of the fused-quartz anvil, $C$, of the tailstock determines the number of threads to be measured. The micrometer screw, $D$, of the headstock has attached to it an arm on the end of which is a pointer that reads divisions on a scale, $F$, which has millimeter divisions, although the photograph shows only centimeter divisions. A millimeter division on the scale corresponds to a motion of the screw of about $1 \mu$, so that $0.1 \mu$ can be estimated. The lamp mounted on the dry cell is extinguished when the force between the anvil and the micrometer screw reaches a definite value. To accomplish this, a hole, drilled along the axis of the micrometer screw, is fitted with a rod which opens a contact, $K$, when a force of about $200 \mathrm{~g}$ is exerted on the rod by the anvil. (See also fig. 6 .)

The bottom view shows the edges, $H H$, the ends of which normally rest in the threads, since the radius of curvature of the edge is less than that of the form. The planes, $P, P$, rest on the top of the form so that both the headstock and the tailstock have a three-point support. 
form with about one-fourth of the length of the lap projecting beyond the end of the form, to start the driving motor in such a direction of rotation that the lap was carried in the threads towards the opposite end of the form, and to reverse the direction of the motor when about one-fourth of the length of the lap projected from the opposite end of the form. When the lap reached its starting position it was removed from the form and turned end for end. This procedure was repeated until the threads appeared to be uniform. The final shape of the threads of both lap and form is shown by profile $C$ in figure 2. The difference between the three profiles in this figure shows the changes in the shape of the threads on both lap and form during the lapping process. The final profile is approximately a sine wave. The wave length was fixed by the original pitch of the threads. The depth of the thread was dependent on the relative rate of grinding of the form and the lap. Preliminary experiments had indicated that a wroughtiron lap on a glass form gave a satisfactory shape and depth for the thread.

\section{MEASUREMENTS FOR UNIFORMITY OF PITCH AND DIAMETER OF THE FORM}

Measurements were made at frequent intervals to determine the uniformity of pitch and the uniformity of diameter of the form. The micrometer for measuring uniformity of pitch is shown in figure 3. A scale division corresponded to about one micron and tenths of microns could be estimated. A description of this micrometer is given later in connection with the measurement of the pitch. The diameter was measured with a machinist's micrometer caliper, which was attached to a frame suitable for resting in the threads of the form. The micrometer was modified by attaching a large head on which readings to tenths of a micron could be made, and by adding a device that permitted all measurements to be made with the same force between the measuring surfaces. For regular measurements of the diameter, wires of the same diameter as the copper wire with which the solenoid was to be wound were held loosely in the threads underneath the faces of the micrometer.

\section{LAPPING TO PRODUCE UNIFORM DIAMETER}

The pitch became very uniform soon after the lapping started. However, the diameter did not become exactly uniform when only the long lap was used. The form had the same diameter at the center and the two ends, but was about $10 \mu$ larger at points intermediate between the center and ends. To reduce these portions, a short lap, shown as $B$ in figure 1, was constructed using blocks removed from the ends of the long lap. This short lap was at first used locally to reduce the larger areas and then followed by the use of the long lap. The alternate use of the two laps was continued until the diameter was uniform throughout to within about $2 \mu$. At this stage of the lapping it was found that the sections of the thread were approximately $3 \mu$ deeper near the bubble openings than elsewhere. The bubble openings were produced in the course of the grinding since numerous small bubbles were near the outer surface. The deepening of the thread was due to a fresh supply of emery grains being fed under the lap from the open bubble. The pressure between the lap and the 
glass quickly reduced the size of the grains so that the thread was deepened for a few centimeters on each side of the open bubble. It was found that this difficulty could be overcome by counterbalancing the weight of the lap, thus reducing the pressure between the lap and the glass to such an extent that there was practically no reduction in the size of the emery grains. This procedure produced threads of uniform depth. The final grinding was completed by using the counterbalanced short lap uniformly over the full length of the cylinder. The rate of grinding with the counterbalanced lap was very slow so that the total change in diameter after the use of the long lap was discontinued was less than $10 \mu$.

\section{DRAWING THE WIRE AND WINDING IT ON THE FORM}

Oxygen-free copper wire was used in constructing the inductor. When purchased the wire had a diameter of about $1 \mathrm{~mm}$. It was drawn through sapphire dies to the required diameter of $0.7 \mathrm{~mm}$. There was a great difference in the drawing quality of wire from different sources. Several manufacturers cooperated in producing wire for this work. Some of the wire which had been very carefully and specially prepared did not have satisfactory drawing qualities, although this was not generally determined until the winding on the form had been completed. A satisfactory winding was obtained with the third specimen of wire.

The procedure for drawing the wire and making a winding was as follows: The wire was wound in a single layer onto a large wooden cylinder about the size of the glass form. The wooden cylinder was mounted in one lathe and a smooth brass cylinder, also of the same diameter as the form, in an adjoining lathe. The wire was drawn through a die onto the brass cylinder, then rewound onto the wooden one. This was continued until only one drawing remained to reduce the wire to the desired diameter. The brass cylinder was then replaced by the glass form and the wire on passing through the last die went directly into the screw thread. The wire was of such diameter that it rested on the sides of the thread without touching the bottom, as shown in insert I of figure 5. Hence it was held firmly in place. The ends of the winding were soldered to brass rods (diameter $3 \mathrm{~mm}$, length $20 \mathrm{~mm}$ ) that had been inserted in holes drilled about $5 \mathrm{~cm}$ from each end of the form. The wire outside of each soldered point was removed, and samples were taken from it for measurements of the diameter of the wire.

\section{POLISHING SPOTS ON THE WIRE AND MAKING RULINGS ON}

When the winding had been completed, a fine, flat oilstone was rubbed along four equally spaced generators of the solenoid by a device held in the tool post of the lathe. This polished small elliptically shaped spots on each turn of the wire, as shown in figure 6 of the previous publication. The length of each spot was in the direction of the axis of the wire at that point and the width of the spot was in the direction of the axis of the solenoid. This is an exceedingly sensitive test of the uniformity of the diameter of the solenoid from turn to turn, since, if the maximum depth of the portion removed is only $1 \mu$, the length of the spot is $1 \mathrm{~mm}$. A change in depth 


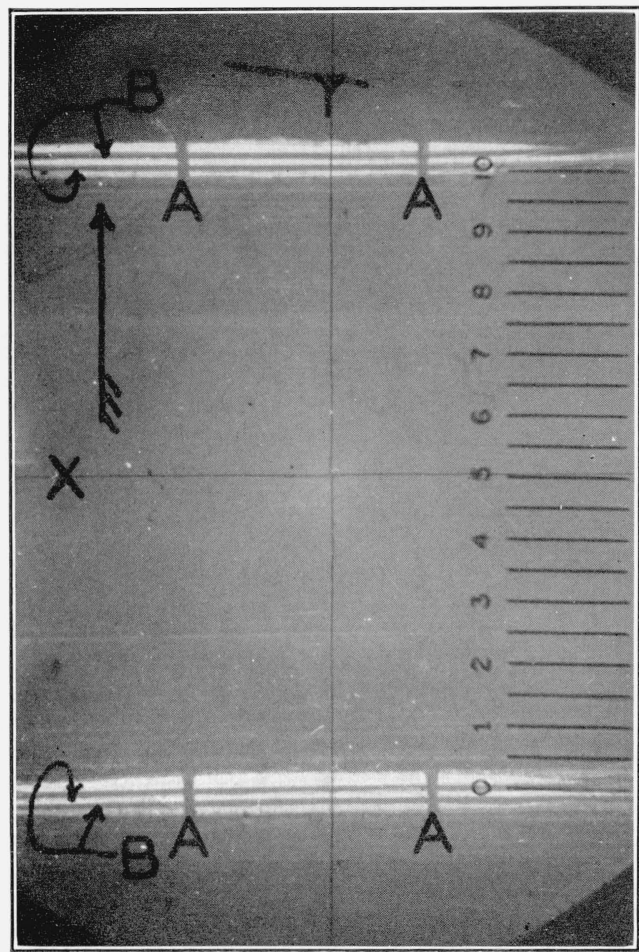

Figure 4.-Photomicrograph showing the spots on two wires and the lines on the spots.

The spots were polished on the wires and the lines made before the solenoid was removed from the lathe in which it was wound. The polishing was accomplished by a single stroke of an oilstone in the direction indicated by the arrow. The lengthwise lines, $B$, were made by a tool which is shown in figure 5 . The crosswise lines, $A$, are parallel to the axis of the solenoid. The numbered scale and the two cross hairs, $X$ and $Y$, were in the ocular micrometer of the microscope. 

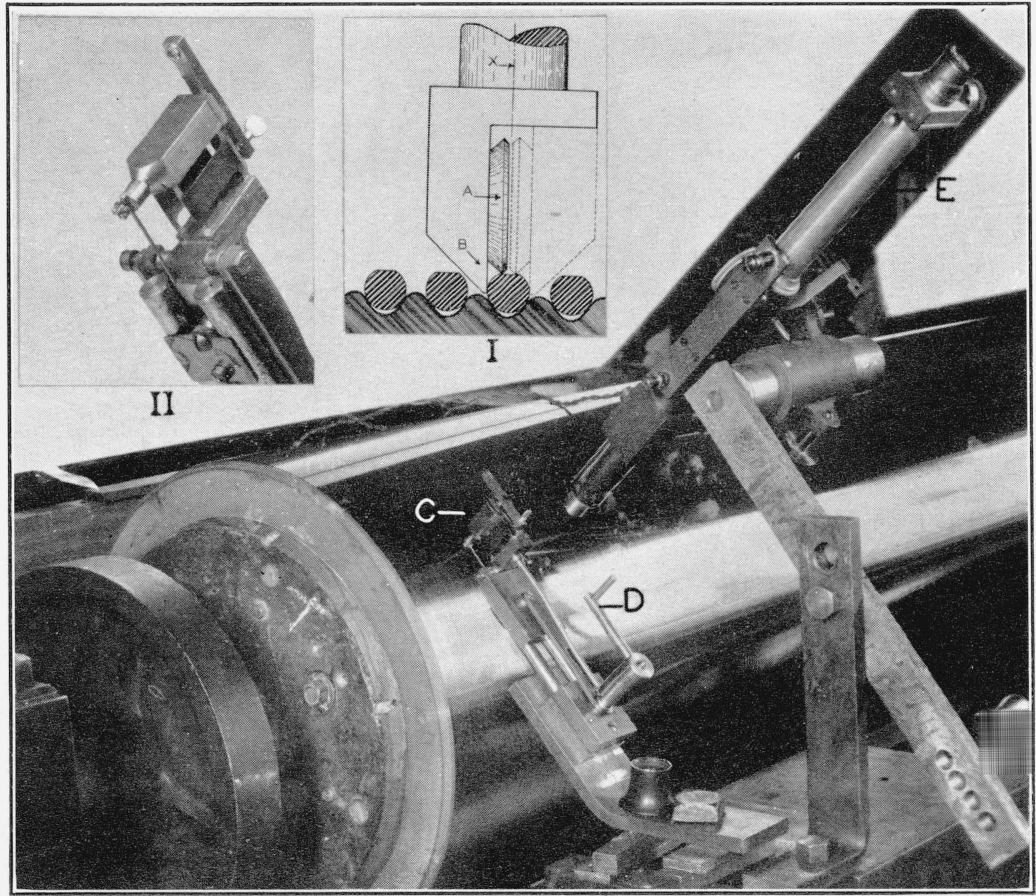

FiguRE 5.-Tool for ruling the lengthwise lines on the spots.

Insert $\mathrm{I}$ is a sketch of the ruling head to show the ruling tool, $A$, which was a hardened steel disk, the guide, $B$, and the axis, $X$, around which the head was rotated to rule the second line on the spot (second position shown in dotted lines)

Insert II is a photograph of the ruling head showing the mounting of the ruling disk and the springs that held the guide against the wire.

The main photograph shows the ruling head, $C$, and accessories mounted on the lathe carriage. One rotation of the crank, $D$, lowers the head, rules a line, and returns the head to its original position. The second rotation of the crank, made after the head was rotated through $180^{\circ}$, ruled the second line. The microscope, $E$, was used in adjusting the ruling head. 
of a spot of $0.1 \mu$ produces a change in length of a spot of $0.2 \mathrm{~mm}$, which is readily detected by the unaided vision. Of the more than 4000 possible spots on this solenoid only one was missing, which was probably at a point where the wire passed over a bubble in the form. The variation in length of the spots was a few tenths of a millimeter, indicating that the variations in diameter of the solenoid from turn to turn were of the order of $0.1 \mu$.

The spots on the wire were also useful in measuring the pitch after lines had been ruled on a large number of them. The rulings on two spots are shown in figure 4. Four lines were ruled on each spot, two lengthwise of the spot and two crosswise. The lengthwise lines were about $5 \mu$ in width and were ruled by a device shown in figure 5 , which was mounted on the lathe carriage. The guide for the ruling point pressed against one side of the wire when one line was being ruled, then turned through $180^{\circ}$ and pressed against the other side of the wire, when the second line was ruled. The crosswise lines were ruled by a device attached to the tool post of the lathe and were made by running the lathe carriage along its bed, so that the ruling point was carried from one end to the other of the solenoid, which was held in a fixed position. These lines, which were parallel to the axis of the solenoid, were used for the same purpose as the longitudinal lines on a meter bar.

\section{MEASUREMENT OF THE DIMENSIONS OF THE INDUCTOR}

The inductor consisted of a helix and its leads. The dimensions required for computing the inductance of a helix are (1) the pitch of the winding, (2) the mean diameter of the helix, and (3) the diameter of the wire. The departure from uniformity of each dimension must be known in order to estimate the resulting error in the computed inductance.

\section{PITCH OF THE WINDING}

The pitch of the winding has been determined by two different methods, which are designated as the micrometer method and the cathetometer method.

\section{(a) MICROMETER METHOD}

The micrometer method is a modification of the one described on page 379 for determining the uniformity of pitch. There were four separate parts to the apparatus, the headstock, the tailstock, and two length standards, one of which was a ball, and the other a cylindrical end standard with spherical ends. The first three are shown diagrammatically in figure 6 . The headstock and tailstock were the same as those used in measuring the variation in pitch. A photograph of these is given in figure 3 . The ball was cemented into a thin sheet of vulcanized fiber, so that it could be easily handled and identified. The end standard was mounted on two frames which rested on the solenoid and which permitted it to move easily in the axial direction.

In making a measurement, the headstock and tailstock were placed on the solenoid at such a distance apart that the end standard could be mounted between them, and were adjusted in their circumferential 


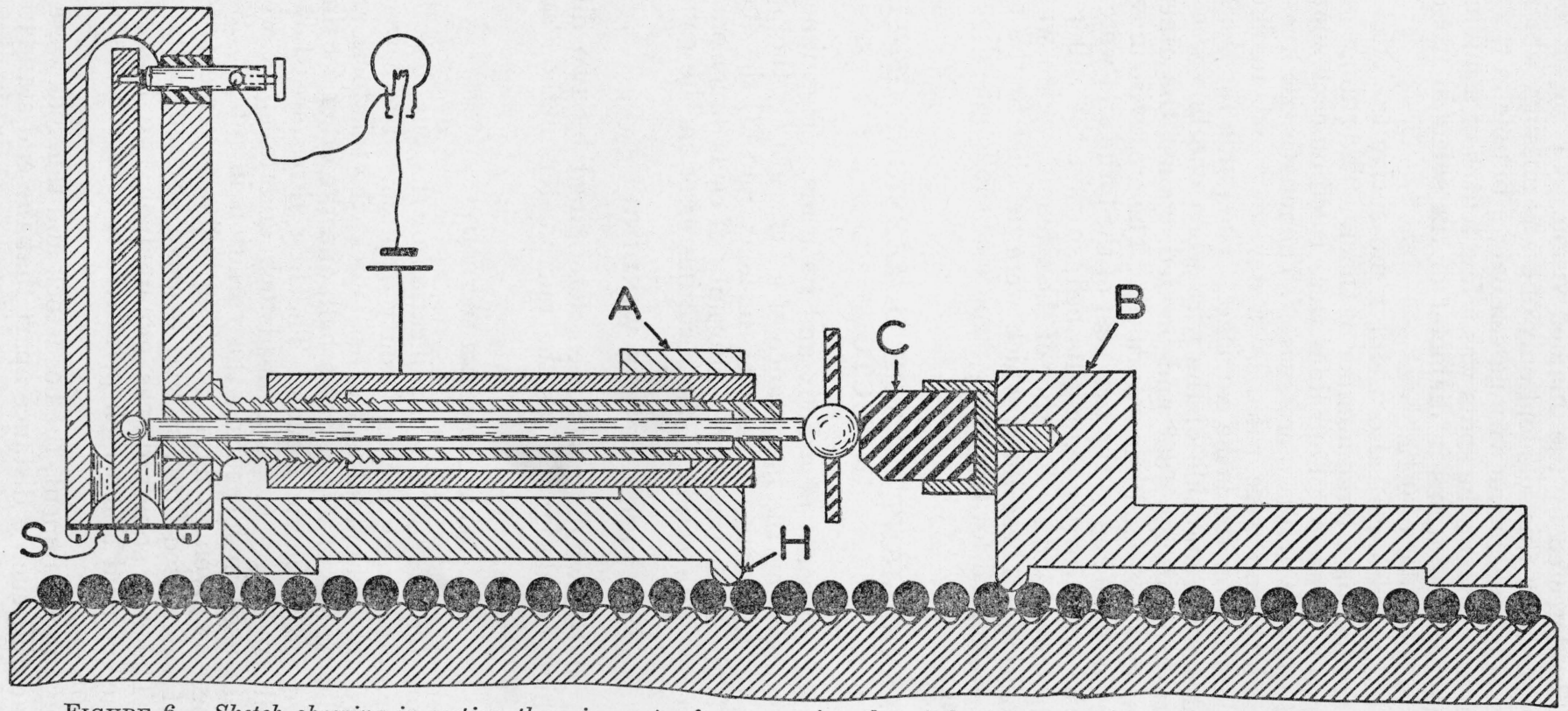

FIGURE 6.-Sketch showing in section the micrometer for measuring the pitch of the solenoid and determining its uniformity.

The headstock, $A$, and the tailstock, $B$, are those used in determining the uniformity of the pitch (see fig. 3 ) except for a shorter anvil, $C$, in the tailstock. The way in which the rod through the micrometer screw opens the contact when the ball is being measured is shown in the diagram. The spring, $S$, keeps the electrical
contact closed. 
positions by means of sensitive levels, on which one graduated division corresponded to $15^{\prime \prime}$ of arc. Several readings were made with the end standard in position. The end standard was then removed and the tailstock (or headstock) moved a definite number of turns, which was determined by the difference between the length of the end standard and the diameter of the ball. The size of the ball was chosen to make the above difference very nearly equal to an integral multiple of the pitch so that the micrometer reading had nearly the same value in both positions of the tailstock. The ball was held between the anvil and the plunger of the micrometer and the micrometer head was turned to make contact with the ball. The force of the micrometer was sufficient to hold the ball in position.

(1) Length standards.- Two different end standards were employed, and with each end standard two balls of quartz and one of steel were used. The end standards were fused-quartz rods having polished surfaces. In each set, one of the quartz balls had a polished surface and the other a fine-ground surface. The essential data on the end standards and balls are given in table 1 .

TABLE 1.-Constants of length standards used in measuring the pitch

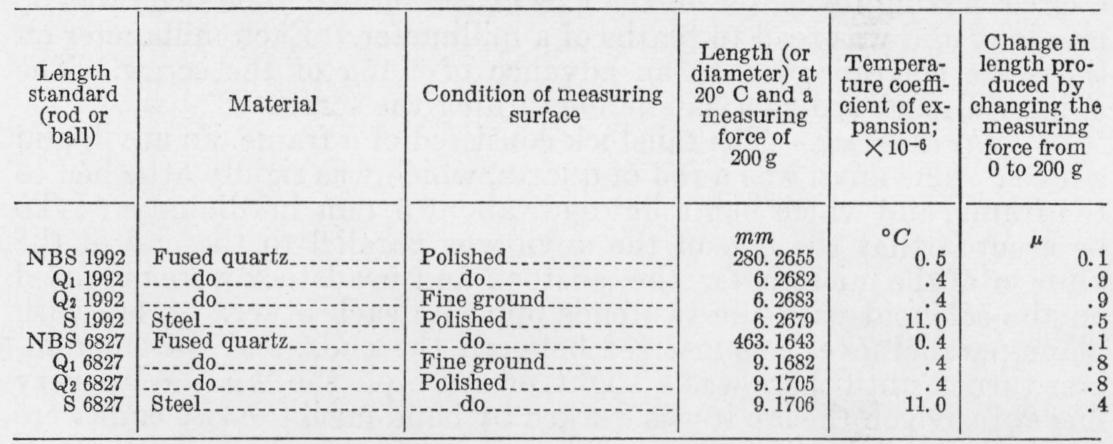

The end standards are designated as NBS 1992 and NBS 6827. The balls have these same numbers with the prefixes $Q_{1}, Q_{2}$, and $S$. The lengths of the end standards were determined ${ }^{2}$ by comparison with calibrated Johansson gages at $20^{\circ} \mathrm{C}$. The lengths at other temperatures were computed by assuming a value for the coefficient of expansion of clear fused quartz. Published values of this coefficient vary from $0.22 \times 10^{-6}$ to $0.62 \times 10^{-6}$ with the most probable value being 0.4 or $0.5 \times 10^{-6}$. The value chosen for one standard was $0.5 \times 10^{-6}$ and for the other $0.4 \times 10^{-6}$, because by using these values the measured pitch of the solenoid at the higher temperatures was the same when determined by the two end standards. As measurements by this method are only a check on the measurements by the cathetometer method, a precise determination of the expansion coefficient did not seem to be warranted.

The compression produced in a standard by the force applied to the measuring faces depends on the material of the standard and is an inverse function of the diameter of the sphere of which it is a part. This is an important consideration in determining the diameter of the balls since they were calibrated with a measuring force of $30 \mathrm{~g}$ and

' See paper by Moon, BS J. Research 10, 249 (1933) RP528. 
used with a force of $200 \mathrm{~g}$. To determine the compression, comparisons were made, using forces of 150 to $600 \mathrm{~g}$ between the faces of the micrometer caliper, with a Johansson gage block, which was assumed to be incompressible. The curve obtained by plotting these data was extrapolated to $30 \mathrm{~g}$.

(2) The headstock.- The micrometer formed an integral part of the headstock, as shown in figure 6. The micrometer screw was the head of a micrometer caliper. A 4-mm hole was drilled axially through the screw. In this hole was fitted a rod with bearings at each end. The rod was prevented from rotating by a fork attached near the end that made contact with the end standard. The opposite end of the rod pressed against the lever arm of a contactor which was fastened to the micrometer screw. As the screw was turned forward after the rod made contact with the end standard, the force exerted by the rod increased. When this force reached $200 \mathrm{~g}$ the spring which held the lever of the contactor would yield a sufficient amount to permit the contacts to open a circuit which contained a battery and a lamp. An advance of the screw of $0.1 \mu$ would open the lamp circuit. A pointer, $88 \mathrm{~mm}$ long, was attached to the micrometer screw. The outer end of the pointer moved along a scale that was an arc of a circle having its center on the axis of the screw. The scale was 50 $\mathrm{mm}$ long and was read to tenths of a millimeter. Each millimeter on the scale corresponded to an advance of $1.15 \mu$ of the screw. The pointer also served as a handle for turning the screw.

(3) The tailstock.-The tailstock consisted of a frame, an anvil, and a level. The anvil was a rod of quartz, which was rigidly attached to the frame, and which had a flat end, about $5 \mathrm{~mm}$ in diameter. To be assured that the end of the anvil was parallel to the end of the plunger of the micrometer, the tailstock and headstock were mounted on the solenoid with the two ends opposite each other. A lap with plane parallel faces was inserted between the ends, and the micrometer turned until there was a slight pressure on the lap. With very fine abrasive on the lap it was worked by hand until the two ends were flat and parallel. This did not, however, necessarily make the two ends exactly perpendicular to the axis of the screw, a requirement that was of no importance because neither the anvil nor the plunger was allowed to turn and because the end standards had spherical ends.

(4) Computation of the pitch.-The pitch was computed from the difference between the length of the end standard and the diameter of the ball; the difference between the two micrometer readings; and the number of turns of wire between the two positions of the tailstock. Because the two readings of the micrometer never differed by more than three divisions ( 1 division $=1.15 \mu$ ), a precise calibration of the micrometer screw was not necessary. The data required for determining the pitch and the method of computing it are illustrated in table 2.

There was a greater variation in the readings on any one ball than in the reading's on the end standard. This condition prevailed in almost every set of data, possibly because the balls were compressed more than the end standard by the measuring force and the small variation in the force produced a greater effect on the balls. 
TABLE 2.-Typical set of readings when using the micrometer to determine the pitch of the long glass inductor after winding

Date: October 10, 1936.

Temperature: (Room with thermostat control) $25.5^{\circ} \pm 0.2 \mathrm{C}^{\circ}$.

Calibration: 1 micrometer division equals $1.15 \mu$.

Observational Data

\begin{tabular}{|c|c|c|c|c|}
\hline Tailstock position $\rightarrow$ & \multicolumn{4}{|c|}{ Turn 619} \\
\hline Headstock position $\rightarrow$ & Turn 75 & & Turn 529 & \\
\hline Length standard $\rightarrow$ & $\begin{array}{l}\text { End standard } \\
\text { NBS } 6827\end{array}$ & $\begin{array}{l}\text { Ball } \\
\mathrm{Q}_{1}\end{array}$ & $\begin{array}{c}\text { Ball } \\
\mathrm{Q}_{3}\end{array}$ & $\begin{array}{c}\text { Ball } \\
\mathrm{S}\end{array}$ \\
\hline Micrometer readings.. & $\begin{array}{l}22.4 \\
22.4 \\
22.4 \\
22.4\end{array}$ & $\begin{array}{l}21.0 \\
21.0 \\
21.1 \\
21.1\end{array}$ & $\begin{array}{l}23.8 \\
23.9 \\
23.6 \\
23.7\end{array}$ & $\begin{array}{l}23.4 \\
23.6 \\
23.6 \\
23.7\end{array}$ \\
\hline$\Delta^{a}\left\{\begin{array}{l}\text { Mean reading } \\
\text { division } \\
\text { microns }\end{array}\right.$ & $\begin{array}{r}22.4 \\
\end{array}$ & $\begin{array}{r}21.0 \\
-1.4 \\
-1.6\end{array}$ & $\begin{array}{r}23.8 \\
+1.4 \\
+1.6\end{array}$ & $\begin{array}{r}23.6 \\
+1.2 \\
+1.4\end{array}$ \\
\hline
\end{tabular}

Computation of Pitch

\begin{tabular}{|c|c|c|c|c|}
\hline Length standard & $\begin{array}{l}\text { Certified } \\
\text { length }\end{array}$ & $\begin{array}{l}\text { Difference in } \\
\text { length be- } \\
\text { tween end } \\
\text { standard } \\
\text { and ball }\end{array}$ & $\begin{array}{l}\text { Length } \\
\text { difference } \\
\text { plus } \Delta\end{array}$ & $\begin{array}{l}\text { Computed } \\
\text { pitch }\end{array}$ \\
\hline $\begin{array}{l}\text { End standard: } \\
\text { NBS 6827 } \\
\mathrm{Q}_{1}-\mathrm{l}_{2}\end{array}$ & $\begin{array}{r}m m \\
463.1654 \\
9.1682 \\
9.1705 \\
9.1711\end{array}$ & \begin{tabular}{l|}
$m m$ \\
453.9972 \\
453.9949 \\
453.9943
\end{tabular} & $\begin{array}{l}m m \\
453.9956 \\
453.9965 \\
453.9957\end{array}$ & $\begin{array}{l}m m \\
1-9.7 \times 10^{-6} \\
1-7.7 \times 10^{-0} \\
1-9.5 \times 10^{-6}\end{array}$ \\
\hline Mean pitch & - & 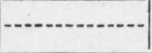 & $n-2-2-2-2$ & $1-9.0 \times 10^{-6}$ \\
\hline
\end{tabular}

a $\Delta$ is reading on ball, minus reading on end standard.

Three different values of the pitch were computed corresponding to readings on the three different balls, but all using the same readings on the end standard. The maximum difference between any two values of the pitch is 2 parts in a million, and the average variation from the mean is less than 1 part in a million.

\section{(b) CATHETOMETER METHOD}

The cathetometer method for determining the pitch of the winding compared the distance between turns with the length of a standard scale. There were two micrometer microscopes attached to the cathetometer pillar that could be rotated about a vertical axis. The two microscopes could be simultaneously pointed either at the standard scale or at the winding of the solenoid. When readings had been made on both solenoid and scale, the distance between the two turns on which readings were made could be obtained and the pitch computed from this distance and the number of included turns.

The modifications from the published ${ }^{3}$ method consisted in using objectives of shorter focal length in the microscopes, in providing two

${ }^{3}$ Moon, J. Research NBS 14, 363 (1935) RP774. 
different methods of illumination, in making readings on lines ruled on the wire, and in redesigning the mounting for the standard scale.

(1) Micrometer microscopes.-The micrometer microscopes had objectives with focal lengths of $32 \mathrm{~mm}$, which increased the magnification in a ratio of nearly 3:1 over that of the older objectives. The accuracy attainable with the $32-\mathrm{mm}$ objectives was tested by a series of observations on a glass scale ruled with 0.1-mm divisions. Four series of readings were made on seven different lines. For each series the microscope was refocused; for two series it was not focused as sharply as possible, but was slightly out of focus to determine the effect on the calibration of the micrometer microscope. The results are given in table 3 .

TABLE 3.-The effect of a change in focus on the calibration of a micrometer microscope with a 32-mm objective

[Readings were made on divisions 0 to 6 of a B\&L stage micrometer]

\begin{tabular}{|c|c|c|c|}
\hline Order of observations & Condition of focus & $\begin{array}{l}\text { Divisions for } \\
0.1 \mathrm{~mm} \text {. Each } \\
\text { result is the } \\
\text { average of } 6 \\
\text { readings }\end{array}$ & $\begin{array}{l}\text { Average } \\
\text { deviation of } \\
\text { the } 6 \text { readings } \\
\text { from their } \\
\text { mean }\end{array}$ \\
\hline $\begin{array}{l}1 \\
2 \\
3 \\
4\end{array}$ & $\begin{array}{l}\text { Best } \\
\text { Closer than best } \\
\text { Farther than best. } \\
\text { Best }\end{array}$ & $\begin{array}{l}128.7 \\
129.4 \\
128.8 \\
129.2\end{array}$ & $\begin{array}{r} \pm 0.7 \\
1.2 \\
0.6 \\
.8\end{array}$ \\
\hline
\end{tabular}

An analysis of these values shows that the accuracy of setting is not appreciably influenced by changes of focus which are sufficiently large to be noticed by the observer.

The lower microscope was calibrated by comparisons with the $0.1-\mathrm{mm}$ divisions on the standard meter bar and also with the graduations on the stage micrometer, referred to in table 3 . The upper microscope was calibrated by comparison with the stage micrometer only. The results are given in table 4 .

TABLE 4.-Calibration of the micrometer microscopes of the cathetometer

[Pitch of screw in micrometer of lower microscope was $0.5 \mathrm{~mm}$; and of upper microscope, $1 \mathrm{~mm}$ ]

\begin{tabular}{|c|c|c|c|c|c|}
\hline Microscope & Reference scale & $\begin{array}{l}\text { Number } \\
\text { of values }\end{array}$ & Observer & $\begin{array}{c}\text { A verage } \\
\text { number of } \\
\text { divisions } \\
\text { for } 0.1 \mathrm{~mm}\end{array}$ & $\begin{array}{l}\text { Average } \\
\text { deviation } \\
\text { in the } \\
\text { values of } \\
\text { a set }\end{array}$ \\
\hline $\begin{array}{l}\text { Upper } \\
\text { Do Do } \\
\text { Do }\end{array}$ & \multirow[t]{2}{*}{$\begin{array}{l}\text { Stage micrometer } \\
\text { do }\end{array}$} & \multirow[t]{2}{*}{$\begin{array}{l}7 \\
7 \\
7\end{array}$} & \multirow[t]{2}{*}{$\begin{array}{l}\text { CM } \\
\text { CMS } \\
\text { CM }\end{array}$} & $\begin{array}{l}128.9 \\
129.0 \\
128.7\end{array}$ & \multirow[t]{2}{*}{$\begin{array}{r} \pm 0.5 \\
1.0 \\
0.7\end{array}$} \\
\hline Mean & & & & 128.9 & \\
\hline $\begin{array}{l}\text { Lower } \\
\text { Do } \\
\text { Do Do } \\
\text { Do }\end{array}$ & \multirow[t]{2}{*}{$\begin{array}{l}\text { Meter bar.... } \\
\text { do } \\
\text { do }\end{array}$} & \multirow[t]{2}{*}{$\begin{array}{l}7 \\
7 \\
7 \\
7\end{array}$} & \multirow[t]{2}{*}{$\begin{array}{l}\mathrm{CMS} \\
\mathrm{CM} \\
\mathrm{CMS} \\
\mathrm{CM}\end{array}$} & $\begin{array}{l}128.9 \\
128.7 \\
129.0 \\
128.5 \\
\end{array}$ & \multirow[t]{2}{*}{$\begin{array}{r}0.5 \\
.4 \\
.4 \\
.3\end{array}$} \\
\hline Mean & & & & 128.8 & \\
\hline Lower & \multirow[t]{2}{*}{ Stage micrometer } & \multirow[t]{2}{*}{$\begin{array}{l}6 \\
6\end{array}$} & \multirow[t]{2}{*}{$\begin{array}{l}\mathrm{CM} \\
\mathrm{CM}\end{array}$} & $\begin{array}{l}128.7 \\
129.1\end{array}$ & \multirow[t]{2}{*}{.8} \\
\hline Mean... & & & & 128.9 & \\
\hline
\end{tabular}


These results show that within experimental error the same calibration is obtained using either the standard meter bar or the stage micrometer as the reference scale. The deviations in a set of observations are less when the meter bar is used as a reference scale, probably because the lines on the meter bar are more favorable for making a setting, although errors in the rulings of the stage micrometer would produce the same result.

(2) Methods of illuminating the scale.-Two different methods of illuminating the scale were employed. In one the lines of the scale appeared in the microscope as dark lines on a bright background. The illuminating attachment which produced this effect was called the bright-field illuminator. In the second, the lines appeared lighter than the background. The attachment in this case was called the dark-field illuminator.

a. Bright-field illuminator.-In the bright-field illuminator, shown near the eyepiece in figure 7 , the light from an illuminated screen was

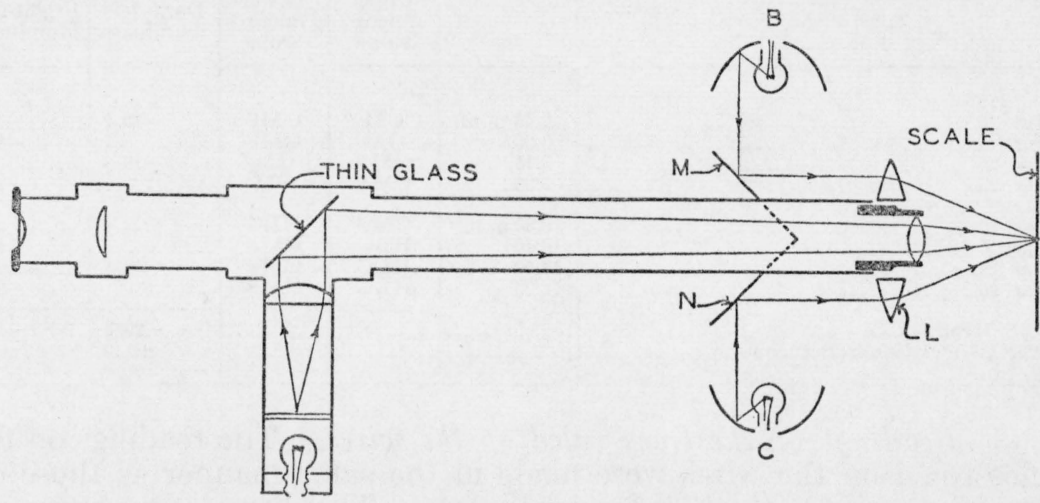

A

FIGURE 7.-Illuminators for a micrometer-microscope of the cathetometer.

The bright-field illuminator of conventional design is shown at $A$. The lamps for the dark-field illuminator are shown at $B$ and $C$, each at the focus of a parabolic mirror. The plane mirrors, $M$ and $N$, meet at an angle of $90^{\circ}$. A hole with its center at the junction of the mirrors admits the tube of the microscope. The lens, $L$, which focuses the light on the scale, also has a hole to admit the microscope.

reflected from a thin sheet of glass placed in the tube of the microscope and at an angle of $45^{\circ}$ with its axis. The light passed through the objective of the microscope and impinged on the scale at nearly normal incidence. Hence the polished surface of the scale returned into the objective a large part of the incident light, whereas the lines did not reflect so large a portion. As a result, the lines of the scale appeared dark on a bright background.

b. Dark-field illuminator.-In the dark-field illuminator, shown near the objective in figure 7 , the light from the lamps on opposite sides of the microscope was reflected from the plane mirrors $M$ and $N$ and was focused on the scale by means of an annular lens, $L$, which was outside of the objective. The light impinged on the scale at a large angle of incidence so that, from the polished surface of the scale, very little light was reflected into the objective. From the lines, however, an appreciable amount of light was diffusely reflected into the objective. As a result, the lines appeared bright on a dark background 
in those portions where the scale was well polished, but where the scale was not well polished the lines could scarcely be distinguished.

c. Comparison of the two illuminators. - Tests were made to determine whether the two methods of illumination gave the same result. The values obtained in the most extensive of these tests are given in table 5. The mean values differ by less than the experimental error. However, the variation is less with the bright-field illuminator, indicating that it is the more accurate of the two methods. The brightfield illuminator was preferred by all of the observers and was used in the majority of the measurements.

TABLE 5.-Distance between wires 51 and 1049 at axial position 1, using different illuminators

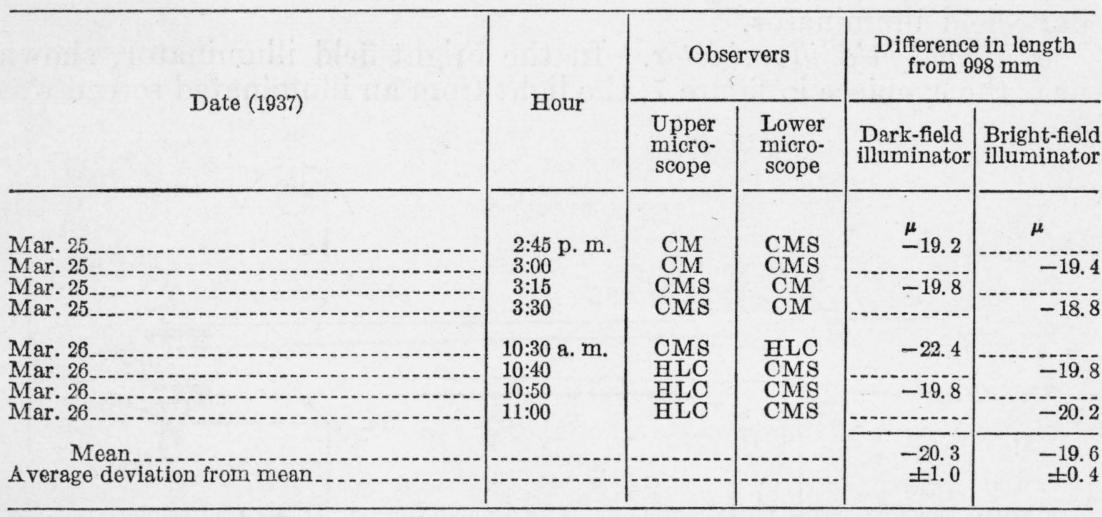

(3) Readings on the lines ruled on the wires.-The readings on the lines ruled on the wires were made in the same manner as those on the graduations of the standard scale. The lines were narrower than the graduations of the scale. This is shown by comparing the lines on the photomicrograph of the spot in $B$ of figure 8 with the graduation $M$ on the photomicrograph of the standard scale in $A$ of figure 8. These photographs were made using the bright-field illuminator by replacing the eye of the observer with a camera.

The single horizontal cross hair of the ocular micrometer is shown at $X$, in figure 8 , and the vertical cross hair at $Y$. They are much narrower than the lines on the scale. Before making a set of observations the vertical cross hair was set midway between the longitudinal lines on the scale or between the two crosswise lines on a spot. Then the horizontal cross hair was adjusted until it coincided with the center of a horizontal line, at a point midway between the vertical lines. The width of the lines on the scale was about $7 \mu$, and of those on the spots about $6 \mu$. In either case, the cross hair could be set with an accuracy of a few tenths of a micron.

The distance between the two lines on a spot was determined for several different spots from the data that were taken in connection with the determination of the pitch. These distances are plotted in figure 9. The lines at axial position 2 were ruled first. These lines were so far apart that they came very near the edges of the spots. The adjustment of the ruling device was changed before making the rulings on axial positions 1,2 , and 4 . The distance between the lines on the spots in axial position 2 averaged $33.3 \mu$ with a maximum deviation of 


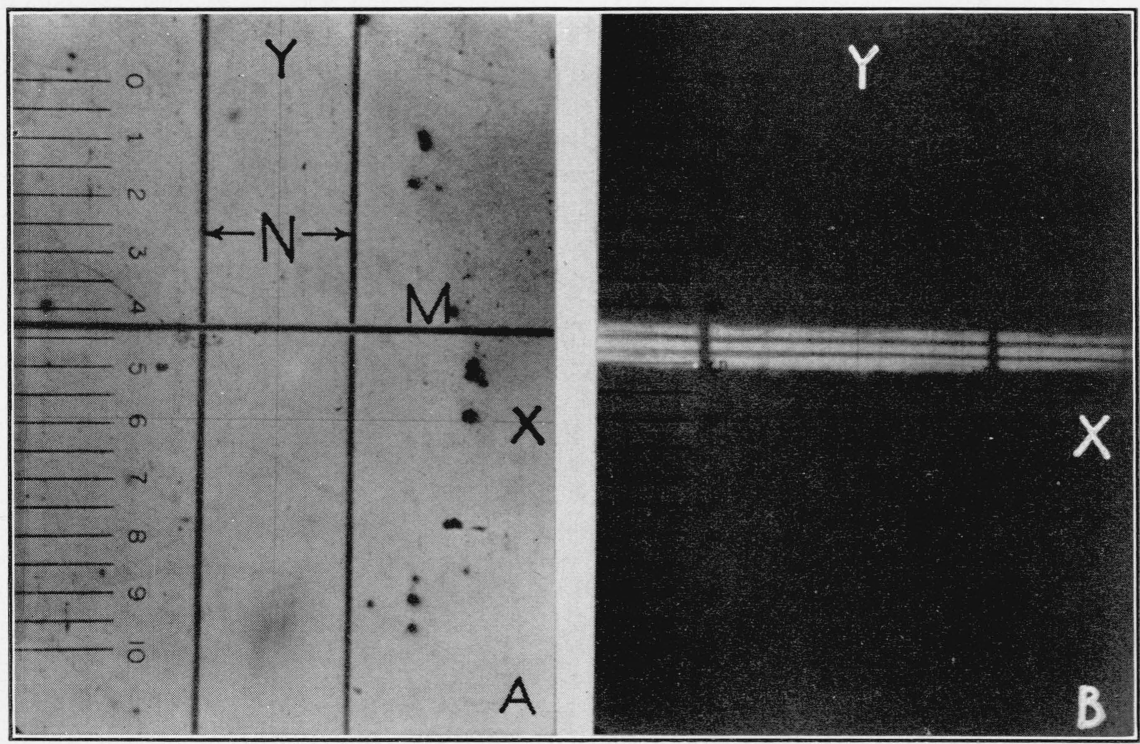

FIGURE 8.-Photomicrographs to show lines on the standard scale and on a spot on the wire as seen through a microscope of the cathetometer. $A$ shows a graduation, $M$, and the two longitudinal lines, $N$, on the standard scale. The black dots are caused by imperfections on the polished surface of the standard scale. $B$ shows a spot on a wire. The lines on the spot were described in connection with figure 4. The numbered scale and the two cross wires, $X$ and $Y$, were in the ocular micrometer of the microscope. 
$1 \mu$. The distance between those on axial positions 1,3 , and 4 averaged $18.5 \mu$, and in no case did it differ from this value by as much as $1 \mu$. The deviations from the mean might have resulted either from errors in measurement, from inaccuracy in ruling the lines, or from variations in the size of the wire. No studies have been made to evaluate the relative importance of these three causes, since the deviations were so small that an error of 1 part in a million could not have been introduced into the value of the pitch by any uncertainty in the positions of the lines.

(4) Mounting for the standard scale.-The standard scale was mounted so that it could be elevated through small distances by

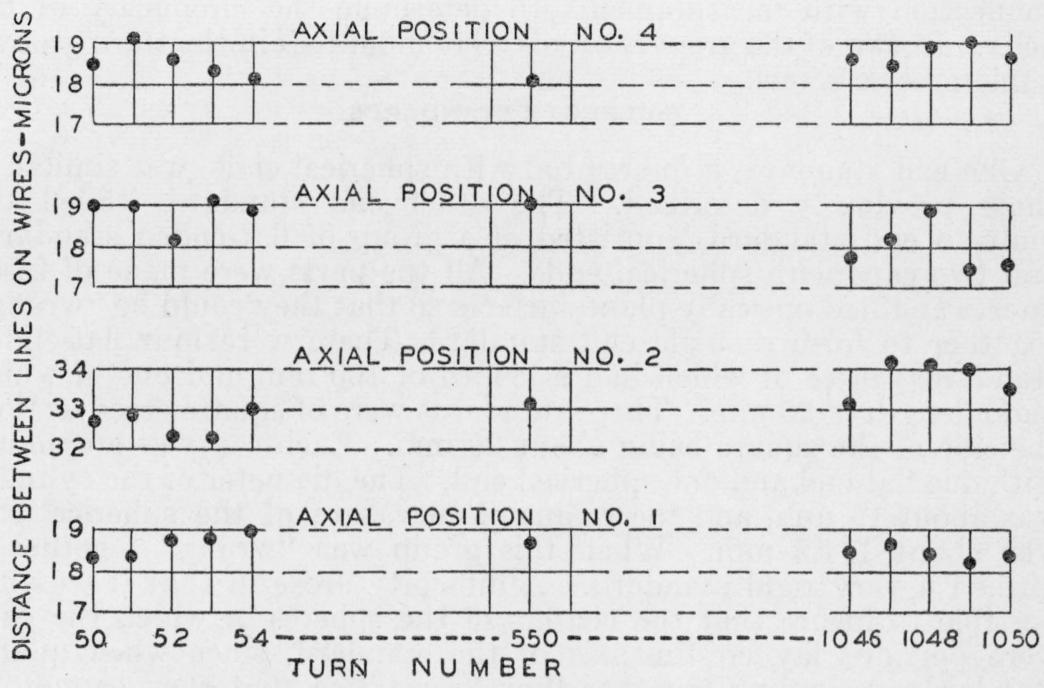

Figure 9.-Distance between the lines on the spots.

means of a screw. It could also be moved laterally to make its position vertical and to bring each end into focus with its microscope.

\section{OUTSIDE DIAMETER OF THE HELIX}

The micrometer used in measuring the outside diameter of the helix was identical in principle with the one used in the previous work. ${ }^{4}$ A new ring was procured by which it was possible not only to measure the diameter of the helix, but also to determine its circularity by a three-point measurement. Two different types of quartz end standards were used, one a rod with spherical ends and the other a built-up standard with spherical caps.

\section{(a) THE MICROMETER}

The ring for the micrometer was of nickel-steel having a coefficient of expansion of about $1.5 \times 10^{-6} /{ }^{\circ} \mathrm{C}$. Its dimensions were: Outside diameter, $48.3 \mathrm{~cm}$; radial width, $4.4 \mathrm{~cm}$; axial thickness, $1.8 \mathrm{~cm}$. The anvil and micrometer screw were of steel having a coefficient of

4 For a diagram of the micrometer, see figure 8, p. 11, of J. Research NBS 16, 1 (1936) RP857.

$94848-38-2$ 
expansion of $11 \times 10^{-6} /{ }^{\circ} \mathrm{C}$. Both the anvil and the micrometer screw extended about $2.5 \mathrm{~cm}$ towards the center from the inner circumference of the ring. The temperature coefficient of expansion of the micrometer as a whole, which can be computed from the preceding values, is $-0.8 \times 10^{-6} /{ }^{\circ} \mathrm{C}$. Readings on the quartz end standard at $20^{\circ}$ and $26^{\circ} \mathrm{C}$ indicate a coefficient of $-1.1 \times 10^{-6}$.

The ring had two pairs of $V$-grooves on two perpendicular diameters and also a group of three $V$-grooves which were spaced $120^{\circ}$ apart. The two pairs of $V$-grooves were used in the measurement of the diameter of the helix. In one pair was mounted the micrometer and the anvil; in the other pair, some stops that were adjusted to keep the ring centered on the helix. The group of three $V$-grooves was used in connection with measurements to determine the circularity of the helix. In two of the grooves anvils were mounted; in the third groove, a micrometer screw.

\section{(b) LENGTH STANDARDS}

One end standard, a quartz rod with spherical ends, was similar to those previously described. The other end standard (called the built-up end standard) consisted of a group of flat-ended standards and two caps with spherical ends. All the parts were made of fused quartz and had optically plane surfaces so that they could be "wrung" together to form a single end standard. There were four flat-ended standards, three of which had a length of $100 \mathrm{~mm}$ and one of which had a length of $25 \mathrm{~mm}$. These standards were of square cross section, the side of the square being about $20 \mathrm{~mm}$. Each cap was a cylinder with one flat end and one spherical end. The diameter of the cylinder was about $19 \mathrm{~mm}$, and the radius of curvature of the spherical end was about $174.2 \mathrm{~mm}$. When this group was "wrung" together it formed a very rigid standard. A difficulty arose in that it was impossible to insure that the centers of the spheres of which the caps were portions lay on the axis of the standard, since when quartz standards are wrung together they "seize," so that they cannot be further adjusted. The centers of the spherical caps need not coincide if the faces of the micrometer are always perpendicular to the axis of the standard, but this requirement could not be accurately fulfilled.

A geometrical analysis was made of an imperfect spherically ended standard to show the change in length caused by changing the position of the standard between the measuring planes. The imperfection considered was that the centers of the two spherical caps did not coincide. It was assumed that each cap had the same radius, but that the sum of the two radii was not exactly equal to the axial length of the standard. It was also assumed that the centers were displaced in a direction perpendicular to the axis of the standard. This analysis showed that the distance $D$ between the measuring planes when there is an angle, $\theta$, between the axis of the standard and the perpendicular to the measuring planes can be represented by the equation

$$
D=D_{0}+\left(Y-X / D_{0}\right) \tan \theta
$$

where $D_{0}$ is the axial length of the standard, $Y$ is the component, in a direction perpendicular to the axis, of the distance between the centers of the two caps, and $X$ is the component, in the direction of the axis, of the same distance, which is positive when the sum of the two radii is less than the axial length. 
This equation shows that a displacement of the centers of the spherical caps perpendicular to the axis of the standard produces a much larger effect than an error of corresponding amount in the radii of the caps.

If two measurements are taken with two values of $\theta$ which differ by $180^{\circ}$, then since $\tan \theta=-\tan \left(180^{\circ}+\theta\right)$,

$$
D_{0}=\frac{D_{1}+D_{2}}{2}
$$

Hence, the effect of this imperfection in the standard should be eliminated by averaging two readings taken with two values of $\theta$, which are $180^{\circ}$ apart. In order to show how nearly the angle $\theta$ must equal zero for the two standards used in measuring the diameter of the long glass inductor, two sets of measurements were made with each standard, one in which $\theta$ was as near zero as could be estimated by visual observations, the other with $\theta$ about $2^{\circ}$. During the measurements, the micrometer was mounted in a comparator, and the standard rotated around its own axis, The results are shown in table 6 . The sets at different angles on any one standard should not be compared, as the measurements were not made under carefully controlled temperature conditions.

TABLE 6.-Micrometer readings on end standards as influenced by the azimuthal position of the standard and by the angle between the axis of the standard and a perpendicular to the measuring faces of the micrometer

A. Built-up End Standard Consisting of Parts "Wrung" Together

\begin{tabular}{|c|c|c|}
\hline \multirow{2}{*}{ Azimuthal position of standard } & \multicolumn{2}{|c|}{ Micrometer reading } \\
\hline & $\begin{array}{l}\text { Angle of } \\
\text { axis }=0^{\circ}\end{array}$ & $\begin{array}{l}\text { Angle of } \\
\text { axis }=2^{\circ}\end{array}$ \\
\hline $\begin{array}{c}\text { Degrees } \\
0 \\
180\end{array}$ & $\begin{array}{l}\mu \\
171.0 \\
171.0\end{array}$ & $\begin{array}{l}\mu \\
179.5 \\
164.6\end{array}$ \\
\hline A verage $\ldots . .$. & 171.0 & 172.0 \\
\hline $\begin{array}{l}90-10-10 \\
270\end{array}$ & $\begin{array}{l}170.8 \\
171.8\end{array}$ & $\begin{array}{l}163.8 \\
179.8\end{array}$ \\
\hline Average..... & 171.3 & 171.8 \\
\hline Grand average....... & 171.2 & 171.9 \\
\hline
\end{tabular}

B. End Standard Consisting of a Rod of Fused Quartz (NBS 5615)

\begin{tabular}{|c|c|c|}
\hline \multirow{2}{*}{ Azimuthal position of standard } & \multicolumn{2}{|c|}{ Micrometer reading } \\
\hline & $\begin{array}{l}\text { Angle of } \\
\text { axis }=0^{\circ}\end{array}$ & $\begin{array}{l}\text { Angle of } \\
\text { axis }=2^{\circ}\end{array}$ \\
\hline $\begin{array}{c}\text { Degrees } \\
0 \\
180\end{array}$ & $\begin{array}{l}\mu \\
142.2 \\
142.2\end{array}$ & $\begin{array}{c}\mu \\
142.5 \\
142.4\end{array}$ \\
\hline A verage..... & 142.2 & 142.45 \\
\hline 90 & $\begin{array}{l}142.2 \\
142.2\end{array}$ & $\begin{array}{l}142.5 \\
142.2\end{array}$ \\
\hline Average.......... & 142.2 & 142.35 \\
\hline Grand average & 142.2 & 142.4 \\
\hline
\end{tabular}


With the built-up standard the average of two measurements at $180^{\circ}$ apart did not differ by more than $0.2 \mu$ from the mean of four measurements taken at $90^{\circ}$ intervals, even when the axis was inclined by as much as $2^{\circ}$. With the standard in the form of a solid rod, the maximum variation of any one measurement did not differ from the mean of four measurements by more than $0.2 \mu$ with the axis inclined, while if the axis were well alined no variation in readings was observed. Hence the end standard from a solid rod of quartz was superior to the built-up standard.

Using the maximum difference found for an azimuthal rotation of $180^{\circ}$, and assuming that this difference was the result of a displacement of the centers of the caps in a direction perpendicular to the axis of the standard, the distance between the centers could be computed for each of the standards by eq 1. For the built-up standard the distance between the centers of the two spherical caps was at least $0.25 \mathrm{~mm}$, while for the quartz rod it was only $0.005 \mathrm{~mm}$.

\section{DIAMETER OF THE WIRE}

The diameter of the wire was obtained by two methods: (a) by measurements with a micrometer caliper, and (b) by computation from the density, mass, and length of a sample. Both of these methods were described in the previous paper. The only modification applied in this later work was the use of a special series of gage blocks for calibrating the micrometer. The new gage blocks were very flat, were not compressed a measurable amount, and were calibrated in terms of wave lengths of light.

\section{OBSERVATIONAL DATA AND RESULTS ON THE MECHANICAL DIMENSIONS OF THE HELIX}

A very large number of observations have been made on each of the mechanical dimensions of the helix. Of these, a sufficient number will be given to enable the reader to determine for himself the accuracy attained. In addition, a summary of all the results will be given.

\section{PITCH OF THE HELIX}

Before the wire was wound on the form, measurements were made by the micrometer method to determine the uniformity of the pitch of the thread and the expansivity of the glass. After the wire was wound on the form, measurements were made by both the micrometer method and the cathetometer method to obtain a value of the pitch which could be used in computing the inductance of the helix.

\section{(a) UNIFORMITY OF THE PITCH OF THE HELICAL THREAD}

Before winding, the uniformity of the pitch of the thread was obtained by measurements of the axial distance between 112 threads at 10 different positions along each of four different generators of the form. The results of 40 readings may be summarized as follows:

Number of readings same as average

Number of readings $0.1 \mu$ different from average

Number of readings $0.2 \mu$ different from average............ 1

Since the readings were made only to $0.1 \mu$, there was no measurable variation in the pitch of the thread. This uniformity was confirmed by similar measurements on 480 threads. 
(b) EXPANSIVITY FROM MEASUREMENTS OF PITCH BEFORE WINDING

Before winding, measurements of the pitch were made by the micrometer method at several different temperatures and with two different end standards. The data are summarized in table 7, and the results are plotted in figure 10. From these data the expansivity of the material of the form was determined to be $2.5 \times 10^{-6} /{ }^{\circ} \mathrm{C}$. This is in exact agreement with the value obtained by the Optical Division of this Bureau for a sample of Pyrex glass which was cast from the same melt as the form.

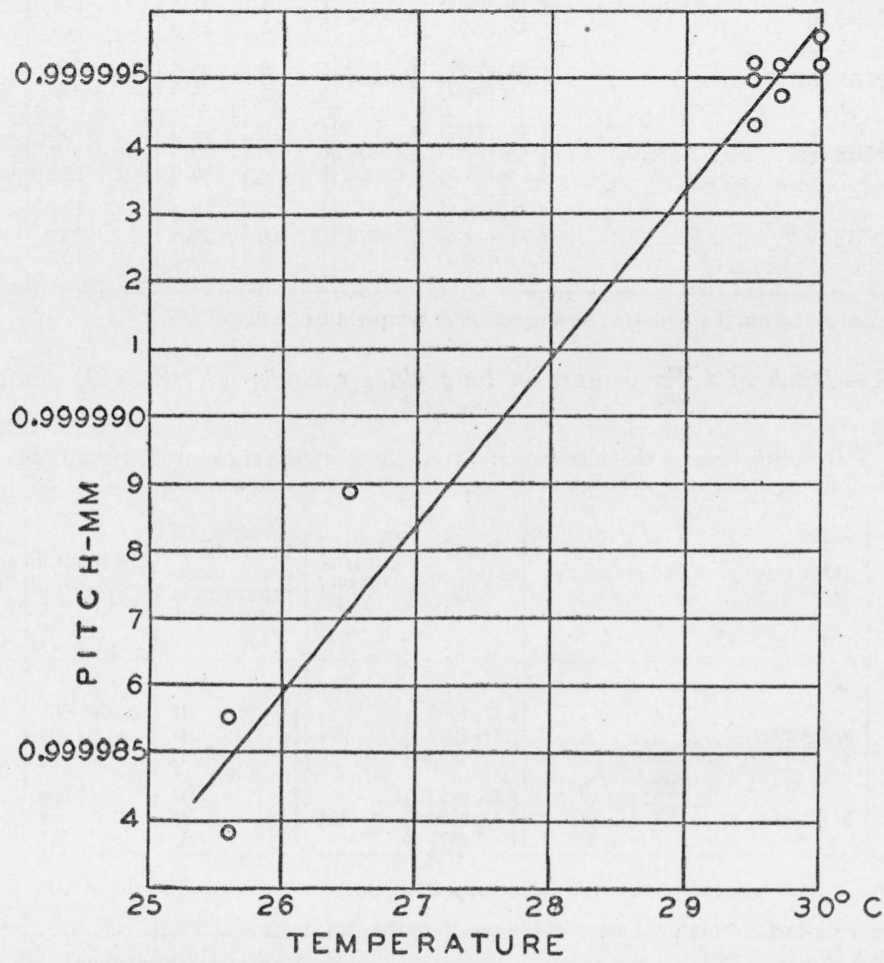

FIGURE 10.-Pitch of the thread on the long glass form as a function of temperature. Measurements were made before winding. The expansivity taken from the slope of the line is $2.5 \times 10^{-6} /{ }^{\circ} \mathrm{C}$.

\section{(c) PITCH AFTER WINDING}

The pitch after winding was determined by the micrometer method and by the cathetometer method.

(1) Micrometer method.- The pitch was determined by the micrometer method using two different end standards and three different balls with each end standard. All measurements were made in a room in which the temperature was controlled day and night at $25.5^{\circ} \mathrm{C}$, and never varied from this temperature by more than $0.5^{\circ} \mathrm{C}$. The solenoid was mounted in the same manner as during the lapping process. The results are summarized in table 8. With each end standard, measurements were made at 11 positions uniformly distributed over the helix. 
TABLE 7.-Pitch (before winding) of the thread on the long glass cylinder (NBS 1847)

\begin{tabular}{|c|c|c|c|c|c|c|c|}
\hline $\begin{array}{l}\text { Date } \\
(1936)\end{array}$ & Designation of end standard & $\begin{array}{c}\text { Designa- } \\
\text { tion of } \\
\text { ball }\end{array}$ & $\begin{array}{l}\text { Num- } \\
\text { ber of } \\
\text { turns }\end{array}$ & $\begin{array}{l}\text { Num- } \\
\text { ber of } \\
\text { obser- } \\
\text { vations } \\
\text { in set }\end{array}$ & $\begin{array}{l}\text { Tem- } \\
\text { pera- } \\
\text { ture }\end{array}$ & Pitch ${ }^{a}$ & $\begin{array}{c}\text { Average } \\
\text { deviation } \\
\text { from mean } \\
\text { of set }\end{array}$ \\
\hline Apr. 10 & NBS 6827 .. & $\mathrm{Q}_{1}(6827)$ & 454 & 16 & $\begin{array}{l}{ }^{\circ} \mathrm{C} \\
26.5\end{array}$ & $\begin{array}{c}m m \\
0.9999889\end{array}$ & $\begin{array}{l}m m \\
\pm 0.9 \times 10^{-8}\end{array}$ \\
\hline 15 & NBS 6827. & $\begin{cases}\mathrm{Q}_{1} & (6827) \\
\mathrm{Q}_{2} & (6827)\end{cases}$ & 454 & $\begin{array}{l}12 \\
12\end{array}$ & $\begin{array}{l}29.7 \\
29.7\end{array}$ & $\begin{array}{l}952 \\
948\end{array}$ & $\begin{array}{l}.3 \\
.7\end{array}$ \\
\hline 15 & NBS $1992 \ldots$ & $\left\{\begin{array}{l}Q_{1}(1992) \\
Q_{2}(1992)\end{array}\right.$ & 274 & $\begin{array}{l}3 \\
3\end{array}$ & $\begin{array}{l}29.5 \\
29.5\end{array}$ & $\begin{array}{l}943 \\
950\end{array}$ & $\begin{array}{l}2.9 \\
1.5\end{array}$ \\
\hline 20 & NBS $6827 \ldots$ & $\begin{cases}\mathrm{Q}_{1} & (6827) \\
\mathrm{Q}_{2} & (6827)\end{cases}$ & 454 & $\begin{array}{l}6 \\
5\end{array}$ & $\begin{array}{l}25.6 \\
25.6\end{array}$ & $\begin{array}{l}855 \\
838\end{array}$ & $\begin{array}{r}0.7 \\
.7\end{array}$ \\
\hline 22 & NBS 6827 & $\left\{\begin{array}{l}\mathrm{Q}_{1}(6827) \\
\mathrm{Q}_{2}(6827) \\
\mathrm{S}(6827)\end{array}\right.$ & 454 & $\begin{array}{l}6 \\
6 \\
6\end{array}$ & $\begin{array}{l}30.0 \\
30.0 \\
30.0\end{array}$ & $\begin{array}{l}956 \\
952 \\
952\end{array}$ & $\begin{array}{l}.3 \\
.4 \\
.4\end{array}$ \\
\hline 22 & NBS $1992 \ldots$ & $\left\{\begin{array}{r}\mathrm{Q}_{1}(1992) \\
\mathrm{Q}_{2}(1992) \\
\mathrm{S}(1992)\end{array}\right.$ & 274 & $\begin{array}{l}6 \\
6 \\
6\end{array}$ & $\begin{array}{l}29.5 \\
29.5 \\
29.5\end{array}$ & $\begin{array}{l}952 \\
952 \\
952\end{array}$ & $\begin{array}{l}.6 \\
.5 \\
.6\end{array}$ \\
\hline
\end{tabular}

a The values of the pitch are plotted as a function of temperature in figure 10.

TABLE 8.-Pitch of helix wound on long glass cylinder (NBS 1847)-micrometer method

[Measuring force on the micrometer: $200 \mathrm{~g}$. Temperature of room: $25.5^{\circ} \pm 0.3^{\circ} \mathrm{C}$ ]

\begin{tabular}{|c|c|c|c|c|c|c|}
\hline $\begin{array}{l}\text { Date } \\
(1936)\end{array}$ & Designation of end standard & $\begin{array}{l}\text { Desig- } \\
\text { nation of } \\
\text { ball }\end{array}$ & $\begin{array}{c}\text { Number } \\
\text { of turns } \\
\text { meas- } \\
\text { ured }\end{array}$ & $\begin{array}{c}\text { Number of } \\
\text { positions at } \\
\text { which meas- } \\
\text { urements } \\
\text { were made }\end{array}$ & $\begin{array}{c}\text { Mean pitch } \\
\text { of set }\end{array}$ & $\begin{array}{l}\text { Average } \\
\text { deviation of } \\
\text { an individ- } \\
\text { ual reading } \\
\text { from mean } \\
\text { of set }\end{array}$ \\
\hline Oct. 12-13.. & NBS 1992_... & $\left\{\begin{array}{rr}Q_{1} & 1992 \\
Q_{2} & 1992 \\
\mathrm{~S} & 1992\end{array}\right.$ & 274 & $\begin{array}{l}11 \\
11 \\
11\end{array}$ & $\begin{array}{r}m m \\
0.9999908 \\
903 \\
909\end{array}$ & $\begin{array}{c}\quad m m \\
\pm 0.9 \times 10^{-6} \\
.8 \\
.8\end{array}$ \\
\hline $14 \ldots$ & NBS $6827 \ldots$ & 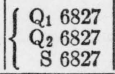 & 454 & $\begin{array}{l}11 \\
11 \\
11\end{array}$ & $\begin{array}{l}902 \\
904 \\
897\end{array}$ & $\begin{array}{r}1.0 \\
0.9 \\
.9\end{array}$ \\
\hline \multirow{2}{*}{\multicolumn{5}{|c|}{ Mean }} & 0.9999904 & $-\ldots$ \\
\hline & & & & Average deviation from final mean of the means of the sets. & - n & $\pm 0.3 \times 10^{-6}$ \\
\hline
\end{tabular}

(2) Cathetometer method.-In determining the pitch by the cathetometer method, measurements were made with the inductor standing on end in a cabinet in which the temperature was maintained at $26^{\circ}$ C. Each measurement was made between a pair of turns, one of which was located near one end of the portion of the winding that was to be used in the electrical measurements, and the other turn near the opposite end. Measurements were made at four different axial positions, and at each axial position five different pairs of turns were observed. In addition, measurements were made between the center turn and turns at each end. The results are summarized in table 9 . 
TABLE 9.-Pitch of helix wound on long glass cylinder (NBS 1847)-cathetometer method

[Standard scale: NBS 3143, length $1.5 \mathrm{~m}$, made by the Sociéte Genevoise and calibrated by the Length Section of this Bureau. Temperature $26.0^{\circ} \mathrm{C}$.]

A. Measurements Between turns Near the Ends

\begin{tabular}{|c|c|c|c|c|c|c|}
\hline \multirow{2}{*}{$\begin{array}{l}\text { Date } \\
(1937)\end{array}$} & \multirow{2}{*}{$\begin{array}{l}\text { Axial } \\
\text { posi- } \\
\text { tion }\end{array}$} & \multicolumn{2}{|c|}{$\begin{array}{l}\text { Turns between } \\
\text { which measure- } \\
\text { ment was made }\end{array}$} & \multirow{2}{*}{$\begin{array}{l}\text { Number } \\
\text { of obser- } \\
\text { vations } \\
\text { in set }\end{array}$} & \multirow{2}{*}{$\begin{array}{l}\text { Mean } \\
\text { piteh }\end{array}$} & \multirow{2}{*}{$\begin{array}{l}\text { Average } \\
\text { deviation of } \\
\text { an individ- } \\
\text { ual reading } \\
\text { from mean } \\
\text { of set }\end{array}$} \\
\hline & & $\begin{array}{l}\text { Bottom } \\
\text { No. }\end{array}$ & $\begin{array}{l}\text { Top } \\
\text { No. }\end{array}$ & & & \\
\hline $\begin{array}{l}\text { Mar. } 25-\text { Apr. } 16 \\
\text { Mar. } 25 \text { and Apr. } 9 \\
\text { Apr. } 5 \text { and } 9 \\
\text { Apr. } 5 \text { and } 9 \text { pr. } 6 \text {, } 9 \text {, and } 16\end{array}$ & 1 & $\begin{array}{l}50 \\
51 \\
52 \\
53 \\
54\end{array}$ & $\begin{array}{l}1050 \\
1049 \\
1048 \\
1047 \\
1046\end{array}$ & $\begin{array}{l}5 \\
2 \\
2 \\
2 \\
3\end{array}$ & $\begin{array}{r}m m \\
0.9999930 \\
33 \\
35 \\
36 \\
39\end{array}$ & $\begin{aligned} & m m \\
& \pm 0.4 \times 10^{-6} \\
& 1.4 \\
& 1.2 \\
& 0.5 \\
& .8\end{aligned}$ \\
\hline $\begin{array}{l}\text { Apr. } 6 \text { and } 16 \\
\text { Apr. } 6 \\
\text { Apr. } 7 \\
\text { Apr. } 7 \text { and } 16 \\
\text { Apr. } 7\end{array}$ & 2 & $\begin{array}{l}50 \\
51 \\
52 \\
53 \\
54\end{array}$ & $\begin{array}{l}1050 \\
1049 \\
1048 \\
1047 \\
1046\end{array}$ & $\begin{array}{l}3 \\
1 \\
1 \\
2 \\
1\end{array}$ & $\begin{array}{l}35 \\
30 \\
48 \\
43 \\
31\end{array}$ & 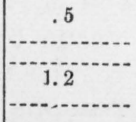 \\
\hline $\begin{array}{l}\text { Apr. } 7 \\
\text { Apr. } 7 \text { and } 8 . \\
\text { Apr. } 7 \\
\text { Apr. } 8 \\
\text { Apr. } 8\end{array}$ & 3 & $\begin{array}{l}50 \\
51 \\
52 \\
53 \\
54\end{array}$ & $\begin{array}{l}1050 \\
1049 \\
1048 \\
1047 \\
1046\end{array}$ & $\begin{array}{l}1 \\
2 \\
1 \\
1 \\
1\end{array}$ & $\begin{array}{l}31 \\
21 \\
36 \\
30 \\
29\end{array}$ & 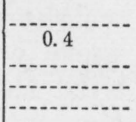 \\
\hline $\begin{array}{l}\text { Apr. } 7 \\
\text { Apr. } 8 \\
\text { Apr. } 8 \\
\text { Apr. } 9 \\
\text { Apr. } 9\end{array}$ & 4 & $\begin{array}{l}50 \\
51 \\
52 \\
53 \\
54 \\
\end{array}$ & $\begin{array}{l}1050 \\
1049 \\
1048 \\
1047 \\
1046 \\
\end{array}$ & $\begin{array}{l}1 \\
1 \\
1 \\
1 \\
1 \\
\end{array}$ & $\begin{array}{l}21 \\
36 \\
31 \\
32 \\
33 \\
\end{array}$ & 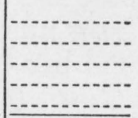 \\
\hline $\begin{array}{l}\text { Final mean } \\
\text { Average deviation of means of sets from }\end{array}$ & nal me & & & - n-n & $0.9999933_{0}$ & $\pm 0.4 \times 10^{-6}$ \\
\hline $\begin{array}{l}\text { Weighted a mean } \\
\text { Weighted a deviation of mean of set fror }\end{array}$ & weighte & mean. & -2 & (n) & $0.9999933_{2}$ & $\pm 0.5 \times 10^{-6}$ \\
\hline
\end{tabular}

B. Measurements Between Midde Turn and End Turns

\begin{tabular}{|c|c|c|c|c|c|c|}
\hline $\begin{array}{l}\text { Apr. } 10,12 \text {, and } 13 \\
\text { Apr. } 12 \text { and } 13 \\
\text { Apr. } 12 \text { and } 13 \\
\text { Apr. } 13\end{array}$ & $\begin{array}{l}1 \\
2 \\
3 \\
4\end{array}$ & 50 & 550 & $\begin{array}{l}3 \\
3 \\
2 \\
1\end{array}$ & $\begin{array}{r}0.9999944 \\
47 \\
28 \\
40\end{array}$ & $\begin{array}{c} \pm 0.7 \times 10^{-6} \\
.4 \\
.2 \\
-.2\end{array}$ \\
\hline Mean of lower half & & & & --- & 0.9999940 & \\
\hline $\begin{array}{l}\text { Apr. } 15 \\
\text { Apr. } 14 \\
\text { Apr. } 14 \\
\text { Apr. } 15\end{array}$ & $\begin{array}{l}1 \\
2 \\
3 \\
4\end{array}$ & 550 & 1050 & $\begin{array}{l}1 \\
1 \\
1 \\
1\end{array}$ & $\begin{array}{r}0.9999918 \\
24 \\
06 \\
26\end{array}$ & 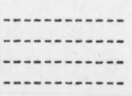 \\
\hline $\begin{array}{l}\text { Mean of upper half } \\
\text { Mean of both halves. } \\
\text { Weighted a mean of all observatio } \\
\text { Corrected for compression of mete }\end{array}$ & & & & - & $\begin{array}{l}0.9999918 \\
0.9999929 \\
0.9999932 \\
0.9999929\end{array}$ & 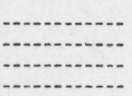 \\
\hline
\end{tabular}

a All weighting was on the basis of the number of observations.

The maximum deviation of any result from the mean was 1.5 parts in a million, and the average deviation about 0.5 part in a million. In the measurements which were made from the bottom turn to the 
center turn and from the center turn to the top turn, the results indicate that the pitch of the lower half of the winding is 2.2 parts per million larger than that on the upper half. This difference is not confirmed by micrometer measurements of variations in pitch, before or after winding. This cannot be accounted for by the compression of the meter bar by its own weight when it is standing on end since the cylinder is compressed in the same way as the meter bar. It can be explained by assuming that the center wire is either displaced or is not quite circular in cross section, or that there is an error in the calibration of the meter bar. This difference is so small that the correction to the computed inductance for the variation in pitch is less than 1 part in a million, even if the assumption is made that the difference indicated in the table is real. Hence the weighted mean of all observations was taken as the value of the pitch by the comparator method.

(3) Most probable value of the pitch of the helix. - The most probable value of the pitch of the helix has been obtained by averaging the results of the two methods. In computing the average there were two reasons for giving the result by the micrometer method a smaller weight than that by the cathetometer method. In the first place, there was more variation in temperature during the measurements with the micrometer than during those with the cathetometer. In the second place, the mounting during measurements with the micrometer might have affected the pitch. This mounting in which an inflated rubber tube held the cylinder in position produced a radial pressure of about $0.4 \mathrm{~kg} / \mathrm{cm}^{2}$ inside the cylinder. A comparison with the lengthening produced by the winding indicated that the shortening caused by the internal pressure might be as much as 0.6 part in a million, although this was not sufficiently definite to warrant making a correction to the observed value. Considering these facts, a weight of unity was assigned to the result by the micrometer method and a weight of two to that by the cathetometer method. Applying this weighting to the values of the pitch already given, the most probable value of the pitch of the helix at $26.0^{\circ} \mathrm{C}$ is

\section{$0.9999924 \mathrm{~mm}$,}

with an uncertainty of less than 1 part in a million.

(4) Increase in the pitch produced by the winding.-The increase in the pitch produced by the winding of the copper wire can be determined from the data in tables 6 and 7 , since the same type of mounting was used in obtaining all these results. From the curve of figure 10, which was plotted from the data of table 6 , the pitch before winding at $25.5^{\circ} \mathrm{C}$ was

$$
0.9999845 \mathrm{~mm} \text {, }
$$

and from table 7 the pitch after winding, at the same temperature, was

\section{$0.9999904 \mathrm{~mm}$}

Hence the increase in pitch was 5.9 parts in a million. This value was not used in computing the inductance, and is given only as a matter of general interest. 


\section{OUTSIDE DIAMETER OF THE HELIX}

The outside diameter of the helix was measured along four different axial planes on two different occasions, different end standards being used on the two occasions. For the first set of measurements the built-up end standard was used. Observations were made at $1-\mathrm{cm}$ intervals along three of the axial planes, while along the fourth they were made at $2-\mathrm{cm}$ intervals on one-half of the length and at $4-\mathrm{cm}$ intervals on the other half. For the second set of measurements the end standard used was made from a rod of fused quartz. Observations were made at $1-\mathrm{cm}$ intervals on all four axial planes; sets of check measurements also were made. The results, for the portion of the winding that was used in making the electrical measurements, are summarized in table 10. The mean of the two sets of measurements gave the outside diameter as

\section{$34.84039_{5} \mathrm{~cm}$.}

The difference between the two sets was $0.5 \mu$. Hence the inductance as computed by using the mean diameter was 1.3 parts in a million smaller than that computed from the first set or the same amount larger than that from the second set. The second set employed a superior end standard to that of the first set, and hence should be given greater weight in the final average. However, the weighting would have to be excessive to change the result by 1 part in a million. For this reason the mean value has been used in computing the inductance.

TABLE 10.-Diameter of the long glass inductor (NBS 1847)

A. Built-up End Standard

[Length at $26^{\circ} \mathrm{C}=34.84171 \mathrm{~cm}$ ]

\begin{tabular}{|c|c|c|c|}
\hline Axial position (degrees) & $\begin{array}{c}\text { Number of } \\
\text { observa- } \\
\text { tions }\end{array}$ & $\begin{array}{l}\text { Average } \\
\text { diameter }\end{array}$ & $\begin{array}{l}\text { A verage devi- } \\
\text { ation of a } \\
\text { single obser- } \\
\text { vation from } \\
\text { mean of set }\end{array}$ \\
\hline $1350^{45}$ & $\begin{array}{r}100 \\
100 \\
101 \\
38\end{array}$ & $\begin{array}{r}c m \\
34.84042 \\
42 \\
43 \\
40\end{array}$ & $\begin{array}{r}\mu \\
\pm 0.4 \\
.4 \\
.4 \\
.5 \\
\end{array}$ \\
\hline Final mean... & -... & 34.84042 & \\
\hline
\end{tabular}

B. End Standard Consisting of a Single Rod of Fused Quartz

[Length at $26^{\circ} \mathrm{C}=34.83888 \mathrm{~cm}$ ]

\begin{tabular}{|c|c|c|c|}
\hline Axial position (degrees) & $\begin{array}{c}\text { Number of } \\
\text { observa- } \\
\text { tions }\end{array}$ & $\begin{array}{l}\text { Average } \\
\text { diameter }\end{array}$ & $\begin{array}{l}\text { A verage devi- } \\
\text { ation of a } \\
\text { single obser- } \\
\text { vation from } \\
\text { mean of set }\end{array}$ \\
\hline $\begin{array}{l}45 \\
135 \\
180\end{array}$ & $\begin{array}{l}101 \\
101 \\
100 \\
101\end{array}$ & $\begin{array}{r}\mathrm{cm} \\
34.84036 \\
37 \\
37 \\
37\end{array}$ & $\begin{array}{r}\mu \\
\pm 0.4 \\
.4 \\
.4 \\
.4\end{array}$ \\
\hline Final mean.... & ...... & 34.84037 & \\
\hline
\end{tabular}

Mean of all measurements............... $34.84039_{5} \mathrm{~cm}$ 
The variation in diameter of the helix is shown by the set of curves given in figure 11. The lower four curves show the variation in the diameter at intervals of $1 \mathrm{~cm}$ on each of four axial planes, the data being those from the second set of measurements. The upper two curves represent the mean diameter at each centimeter along the axis. The scale is very open; one division representing a micron, so that tenths of microns can be estimated.

The curves show that the maximum variation from the mean is less than $2 \mu$, and the data in table 10 give the average variation from the mean for the measurements in any axial plane as $0.4 \mu$ in all but one case, which did not include a complete set of data. This $0.4 \mu$ is the result of imperfections in construction as well as errors in measurement. To determine the errors in measurement, two sets of check measurements were made, each set consisting of 50 independent measurements. The results of these measurements are shown in table 11. In order to indicate the differences in the two sets, results have been carried to hundredths of microns, though the absolute value is not known with that accuracy. The difference in one set is $0.07 \mu$, while in the other it is only $0.01 \mu$. This shows that the accuracy of measurement is greater than $0.1 \mu$, or 3 parts in 10 million.

TABLE 11.-Determinations of the accuracy of a set of measurements of the diameter of the long glass inductor (NBS 1847)

[Each set consisted of 50 measurements on the upper half of the cylinder]

\begin{tabular}{|c|c|c|}
\hline \multirow{2}{*}{ Set } & \multicolumn{2}{|c|}{ Average diameter at axial positions } \\
\hline & $90^{\circ}$ & $180^{\circ}$ \\
\hline $\begin{array}{l}\text { Initial_- } \\
\text { Check-a }\end{array}$ & $\begin{array}{r}c m \\
34.840390 \\
391\end{array}$ & $\begin{array}{r}c m \\
34.840394 \\
387\end{array}$ \\
\hline Difference_........... & $0.01 \mu$ & $0.07 \mu$ \\
\hline
\end{tabular}

Where a bubble in the glass occurred at the surface of the form the wires would tend to be straight where they crossed the bubble opening. When such a bubble was at one end of a diameter the measured value of the diameter of the solenoid would be less than the diameter at the other azimuths of the same cross section. These bubbles could not be seen after the winding was completed, so could not be avoided in making these measurements. Of the several hundred measurements of diameter, there is only one value that is sufficiently different from those obtained at nearby points to indicate that there was probably a bubble under one of the measuring faces of the micrometer.

\section{CIRCULARITY OF CROSS SECTIONS OF THE SOLENOID}

The circularity of cross sections of the solenoid at different elevations was studied (1) by measuring the diameter in different axial planes and (2) by determining the difference in altitudes of circumscribed equilateral triangles.

The average outside diameter of the solenoid, as given in table 10, is the same, within experimental error, for all axial planes. All the 


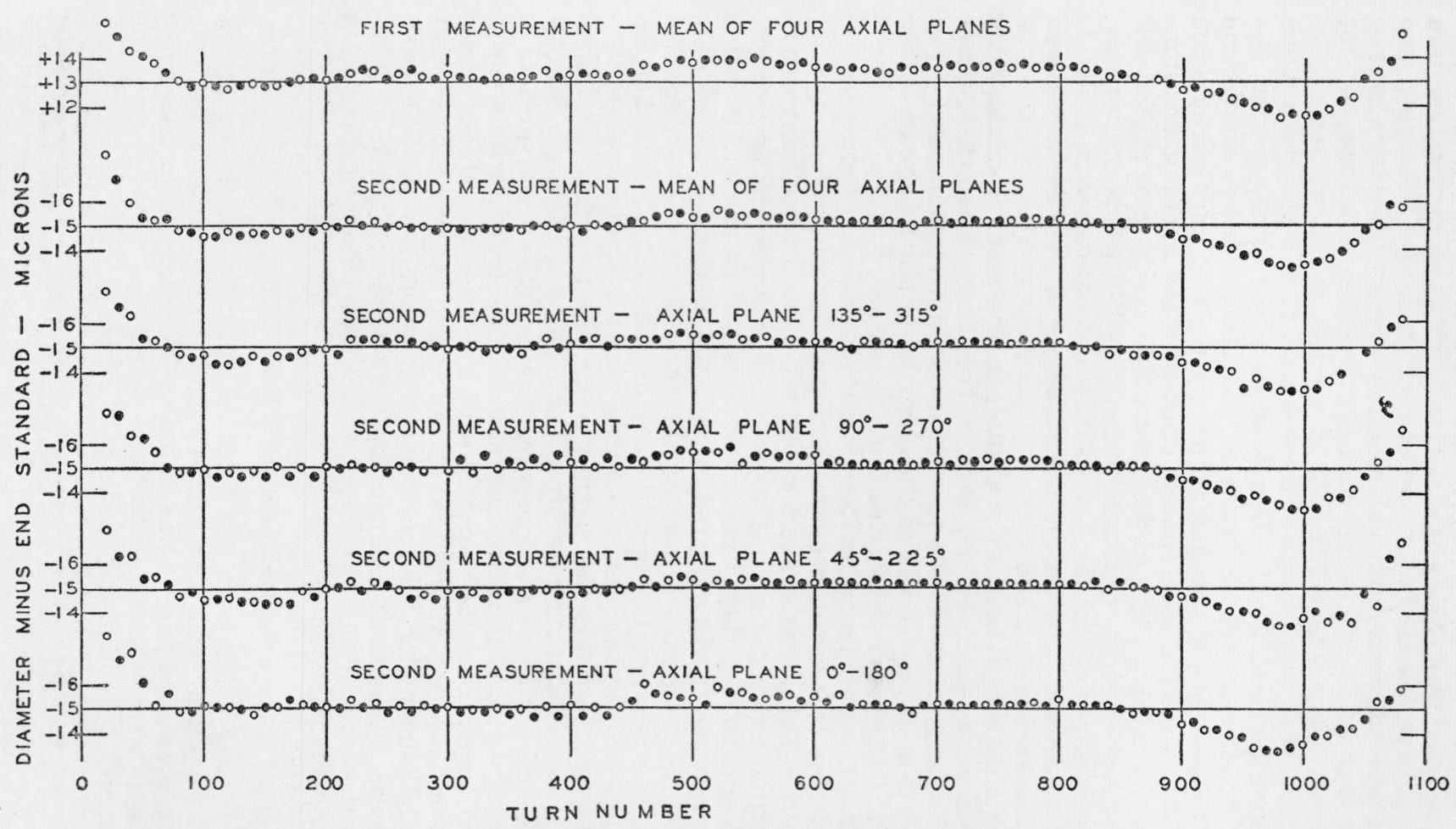

FIGURE 11.-Variation in the diameter of the long glass inductor.

The ordinates are the length of the end standard less the diameters of the inductor. Lengths of end standards-

For first measurement. 348417.1 microns.

The readings obtained in a set of observations on the even centimeters along its length are indicated by circles; those in a second set on a different day, on the odd centimeters, by dots. 
curves of figure 11 have the same shape, showing that there can be very little variation in the diameter when measured at any elevation. This is confirmed by an analysis of the data. The maximum difference from the mean diameter in any set of four readings at one elevation was $0.5 \mu$, and the maximum value of the average deviation at any elevation was $0.35 \mu$. The mean of the average deviations at 101 different elevations was $0.12 \mu$. As these results are within experimental error, the cross section of the solenoid at any plane is a figure having equal diameters, but it is not necessarily a circle.

The difference in the altitudes of the circumscribed equilateral triangles of the solenoid was determined by the ring micrometer when fitted with two anvils each spaced $120^{\circ}$ from the micrometer screw. At any position the reading of the micrometer screw was proportional to the altitude of this equilateral triangle. With this micrometer, observations for determining the change in altitude were made at eight different points around the circumference of the solenoid at each of three different elevations.

The maximum variation of the altitude in any plane from the mean in that plane was $0.2 \mu$, and for each of the three planes the average variation was $\pm 0.1 \mu$. These results are within experimental error, indicating that at any elevation the altitudes of all the circumscribed equilateral triangles of the solenoid are the same.

The measurements just described do not prove that the cross section of the solenoid is a circle, because there may be other plane figures ${ }^{5}$ which have equal diameters and which will fit at all positions within a given equilateral triangle. A more conclusive but less precise test for the circularity of the solenoid was obtained from measurements on the form when it was mounted in the lathe preparatory to winding the wire. As the form was rotated the variation in the reading of a dial gage, which pressed against the top of a thread, was less than $5 \mu$, the smallest reading that could be made with the available gage.

In order to determine the maximum amount by which the inductance of this helix could possibly differ from one having a strictly circular section, there were computed the periphery and area of a Reuleaux triangle ${ }^{6}$ of the same diameter as the helix and with a variation in radius equal to the upper limit of the observed values. Since the periphery is identical with that of a circle and the area only about 1 part in a billion smaller, the conclusion is drawn that even if the cross section were a Reuleaux triangle the inductance of the helix computed on the assumption that the cross section is circular cannot be in error by 1 part in a million.

\section{DIAMETER OF THE WIRE}

The diameter of the wire was determined by two methods: (a) by direct measurement with a micrometer and (b) by computation from the length, mass, and density of a sample. The samples for measuring the diameter were taken from the wire which was removed from the beginning and the end of the winding.

\footnotetext{
${ }^{3}$ Legros, The gauging of cylinders for diameter, Engineer, 151, 436 (1931). In this article is shown a five-sided figure which has equal diameters and which is said to turn inside a regular hexagon. Presumably it would also turn inside an equilateral triangle, but the method of construction is not sufficiently well described to permit of a definite conclusion in this respect.

${ }^{\circ}$ This is a three-lobed figure which has equal diameters when measured between planes. See reference in footnote 5 .
} 
(a) DIAMETER OF THE WIRE BY THE MICROMETER METHOD

In determining the diameter of the wire by the micrometer method, three samples from each end were measured. These samples were about $40 \mathrm{~cm}$ long. The 3 samples from each end were separated from each other by 1 or more turns, but all were within 10 turns of the portion that was left on the cylinder, and 1 was within 1 turn.

The diameter of each specimen was measured at not less than four nor more than six positions along the wire, the distance between positions being about $1 \mathrm{~cm}$. At each position the measurements were made in at least 8 equally spaced axial planes and at 2 positions on each specimen in 16 axial planes. The curvature introduced in winding the wire was such that the inside arc of each sample could be used as a reference line, from which the azimuths were numbered. The means at each azimuth for the three samples from each end are given in table 12, together with the average deviation, at each azimuth, of the value for a sample, from the mean of the three samples. The results given in table 12 are plotted in figure 12.

TABLE 12.-Diameter of wire on glass inductor (NBS 1847)

Date: May 4 and 14, 1937.

Temperature of room: about $25^{\circ} \mathrm{C}$.

Measuring force: 600 g. 1

Tension on wire during measurements: $6.5 \mathrm{~kg}$.

Tension on wire during drawing: $8 \mathrm{~kg}$.

\begin{tabular}{|c|c|c|c|c|c|}
\hline Azimuth & $\begin{array}{c}\text { Average } \\
\text { diameter } \\
\text { at beginning } \\
\text { of winding, } \\
\text { using } 3 \text { sam. } \\
\text { ples }\end{array}$ & $\begin{array}{c}\text { Average } \\
\text { deviation } \\
\text { from mean } \\
\text { of the mean } \\
\text { for each sam- } \\
\text { ple }\end{array}$ & $\begin{array}{c}\text { Average } \\
\text { diameter } \\
\text { at end of } \\
\text { winding, } \\
\text { using } 3 \text { sam- } \\
\text { ples }\end{array}$ & $\begin{array}{c}\text { Average } \\
\text { deviation } \\
\text { from mean } \\
\text { of the mean } \\
\text { for each sam- } \\
\text { ple }\end{array}$ & $\begin{array}{c}\text { Increase in } \\
\text { diameter } \\
\text { of wire at } \\
\text { end over that } \\
\text { at begin- } \\
\text { ning }\end{array}$ \\
\hline $\begin{array}{l}\text { Degrees } \\
011 \\
1122 \\
45\end{array}$ & \begin{tabular}{r}
\multicolumn{1}{l}{$\mu$} \\
720.07 \\
719.92 \\
.85 \\
.68 \\
.54
\end{tabular} & $\begin{array}{r}\mu \\
\pm 0.01 \\
.06 \\
.09 \\
.11 \\
.04\end{array}$ & $\begin{array}{r}\mu \\
720.45 \\
.33 \\
.26 \\
.00 \\
719.91\end{array}$ & $\begin{array}{r}\mu \\
\pm 0.04 \\
.09 \\
.12 \\
.03 \\
.06\end{array}$ & $\begin{array}{r}\mu \\
0.38 \\
.41 \\
.41 \\
.32 \\
.37\end{array}$ \\
\hline $\begin{array}{l}56 \\
69 \\
901 \\
101\end{array}$ & $\begin{array}{r}.48 \\
.69 \\
.70 \\
720.13 \\
.45\end{array}$ & $\begin{array}{r}.08 \\
.06 \\
.20 \\
.18 \\
. \quad .13\end{array}$ & $\begin{array}{r}.95 \\
.97 \\
720.00 \\
.39 \\
.88\end{array}$ & $\begin{array}{l}.03 \\
.04 \\
.10 \\
.17 \\
.14\end{array}$ & $\begin{array}{l}.47 \\
.28 \\
.30 \\
.26 \\
.43\end{array}$ \\
\hline $\begin{array}{l}112 \\
124 \\
135 \\
146\end{array}$ & $\begin{array}{r}.58 \\
.65 \\
.33 \\
719.77 \\
.82\end{array}$ & $\begin{array}{l}.08 \\
.07 \\
.28 \\
.04 \\
.12\end{array}$ & $\begin{array}{r}721.25 \\
720.41 \\
.07 \\
.08\end{array}$ & $\begin{array}{l}.04 \\
.24 \\
.24 \\
.08 \\
.16\end{array}$ & $\begin{array}{l}.67 \\
.47 \\
.08 \\
.30 \\
.26\end{array}$ \\
\hline $\begin{array}{l}169 \\
180\end{array}$ & $\begin{array}{r}.98 \\
720.07\end{array}$ & $\begin{array}{l}.16 \\
.02\end{array}$ & $\begin{array}{r}.43 \\
.45\end{array}$ & $\begin{array}{r}.05 \\
.04\end{array}$ & $\begin{array}{l}.45 \\
.38\end{array}$ \\
\hline Mean & 719.98 & \pm 0.10 & 720.29 & \pm 0.10 & 0.31 \\
\hline
\end{tabular}

Final mean diameter of wire $720.1 \mu$

1 Measurements made with $200 \mathrm{~g}$ show that the same value was obtained as with $600 \mathrm{~g}$.

The micrometer was calibrated by means of a gage block which had a thickness of $0.7001 \mathrm{~mm}$ and which was "wrung" onto the face of the micrometer screw. The micrometer was similar to the one used in measuring the diameter of the solenoid. The scale was graduated 
so that microns could be read directly and tenths of microns could be estimated. Readings at the same point seldom differed by more than $0.2 \mu$. The average values in table 12 have been carried to $0.01 \mu$ in order to indicate differences.

The curves of figure 12 show that, although the wire had a larger diameter at the end than at the beginning, the shape of the cross section apparently changed very little. The uniformity in shape at the two ends can be explained by assuming that the opening in the die wore away evenly by $0.3 \mu$ in drawing the kilometer of wire re-

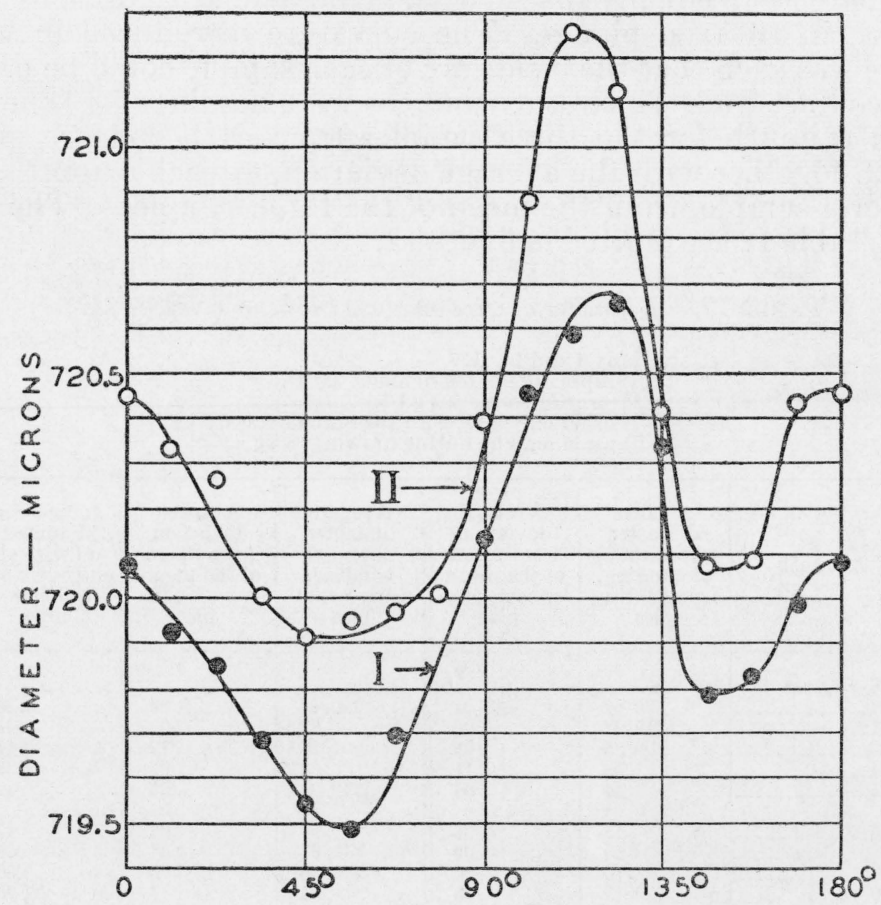

$A Z I M U T H$

FIGURE 12.-Diameters of the wire in different azimuths.

Curve $I$ is for wire from the beginning of the winding. Curve II is for wire from the end of the winding. The diameter of the wire at azimuth $90^{\circ}$ was, before removal from the inductor, in the direction of a radius of the inductor.

quired to wind the helix. Another explanation is that the temperature of the die and of the lubricant gradually changed during the drawing. Since the wire was sufficiently circular in cross section and uniform throughout its length so that average values of the diameter could be used in computing the inductance, no effort was made to find the cause of the small observed changes. If the diameter of the wire at the beginning of the winding (or at its end) had been used to compute the inductance, the result would have been less than 1 part in a million different from that obtained by using the mean value of the diameter of the wire.

The shape of transverse cross sections of the wire was also studied by means of photomicrographs. The wire was plated with nickel so that the outer surface could be easily distinguished, then plated with 
a heavy coating of copper to give it rigidity. Four wires which had been so prepared (two samples from the beginning of the winding and two from the end) were mounted in a single block of solder, and the cross section was polished and etched. Photomicrographs were made of all these samples, using magnifications of 100,250 , and 1000 diameters. Typical photomicrographs are given in figure 13. In the upper photograph, in which the magnification is 100 diameters, the entire cross section is shown. It is difficult, even with a lens, to observe any irregularity in the periphery of the cross section. In the second photograph is shown the most irregular portion of the same wire as that shown in the upper photograph but with a magnification of 1000 diameters. In this picture small irregularities can be observed in the periphery. The maximum variation of the periphery from a smooth curve was less than $1 \mu$. The irregularities in the surface of the wire would probably affect the computed inductance by much less than 1 part per million. A comparison of these photomicrographs with those ${ }^{7}$ given in the previous publication shows the decided improvement that has been made in the uniformity of the surface of the wire.

The photomicrographs with a magnification of 250 diameters were made on glass plates in order that measurements could be made on the diameter of the image. Data were obtained for all four samples. The curves plotted from these data were smooth, but the variations in diameter were several times the average variation observed by the micrometer method. This can be explained either as being caused by imperfections in the optical system used to make the photomicrographs, or as resulting from a slight angle between the axis of the wire and the normal to the polished surface so that the observed cross section is not exactly a transverse cross section of the wire. These measurements on the photomicrographs qualitatively confirm the conclusions drawn from the measurements with the micrometer. However, the accuracy with which measurements on the photomicrographs could be made was so much less than with the micrometer that no data are given.

(b) DIAMETER OF THE WIRE FROM THE LENGTH, MASS, AND DENSITY

The mean diameter of the wire from the length, mass, and density and the data used in computing it, are given in table 13.

TABLE 13.-Diameter of the wire from the length, mass, and density

\begin{tabular}{|c|c|c|c|c|}
\hline Sample & Length & Mass & Density & $\begin{array}{l}\text { Mean diam- } \\
\text { eter of wire }\end{array}$ \\
\hline $\begin{array}{l}\text { Beginning of winding } \\
\text { End of winding }\end{array}$ & $\begin{array}{l}c m \\
327.80 \\
327.77\end{array}$ & $\begin{array}{c}g \\
11.9016 \\
11.9115\end{array}$ & $\begin{array}{l}\mathrm{g} / \mathrm{cm}^{3} \\
8.925 \\
8.925\end{array}$ & $\begin{array}{r}\mu \\
\quad 719.70 \\
720.03\end{array}$ \\
\hline
\end{tabular}

The mean diameter at the end of the winding as given by this method was $0.3 \mu$ larger than at the beginning of the winding, which agrees with the difference obtained by the measurements with the micrometer. However, both at the beginning and at the end, the micrometer method gave a larger diameter than the density method; the amount, by chance, being $0.3 \mu$, the same as the difference in

\footnotetext{
7 See figure 22 opposite p. 61 and figure 27 opposite p. 74 of the previous paper. J. Research NBS 16, 1 (1936) RP857.
} 
diameter between the two ends. The smaller diameter which was obtained by the density method probably resulted from striae which were produced on the wire when it was drawn. Measurements made on the photomicrographs indicated that this is a reasonable explanation. However, in previous work the diameter determined by the density method was $0.6 \mu$ less than by the micrometer method. This would lead to the expectation that the wire used on the long glass inductor had fewer striae than that on the inductors described in the previous report. That such is the case can be seen by comparing the photomicrographs of figure 13 with similar ones of the earlier publication. ${ }^{8}$

Although the density method of determining the diameter of the wire was of interest in showing its uniformity, the result by this method was not used in the computation of the inductance. The important use of the diameter of the wire was in determining the mean diameter of the helix. This was obtained by subtracting the diameter of the wire from the outside diameter of the helix. Since the outside diameter of the helix was measured with a micrometer, it seemed proper to use the diameter of the wire as measured by the same method in obtaining the mean diameter, although the use of the average value from the two methods would have changed the computed inductance by only a little more than 1 part in a million.

\section{COMPUTATION OF THE INDUCTANCES}

The inductances to be computed were those of the helix and its leads and of the substitution inductor. The latter consisted of parallel wires having a resistance equal to the resistance of the helix and its leads.

\section{INDUCTANCE OF THE HELIX}

The inductance of the helix has been computed by Snow's formula. ${ }^{9}$ The measured constants were:

\begin{tabular}{|c|c|c|}
\hline Quantity & Symbol & Value \\
\hline $\begin{array}{l}\text { Mean diameter of helix } \\
\text { Diameter of wire } \\
\text { Pitch of winding } \\
\text { Number of turns. }\end{array}$ & $\begin{array}{l}D \\
d \\
g \\
N\end{array}$ & $\begin{array}{l}\text { 34. } 76838_{5} \mathrm{~cm} \\
.07201 \mathrm{~cm} \\
.09999924 \mathrm{~cm} \\
1000.000\end{array}$ \\
\hline
\end{tabular}

The values of the terms in Snow's equation and the inductance of the helix, $L_{h}$, were, when using the above constants,

$$
\begin{aligned}
& L_{0}=103479707 \mathrm{~m} \mu \mathrm{h} \text {. } \\
& L_{1}=-123470 \\
& L_{2}=\quad-0.2 \\
& L_{3}=\quad-162 \pm 91 \\
& L_{4}=\quad-6 \\
& L_{5}=\quad 490 \\
& \bar{L}_{h}=103356559 \pm 91 \mathrm{~m} \mu \mathrm{h} .
\end{aligned}
$$




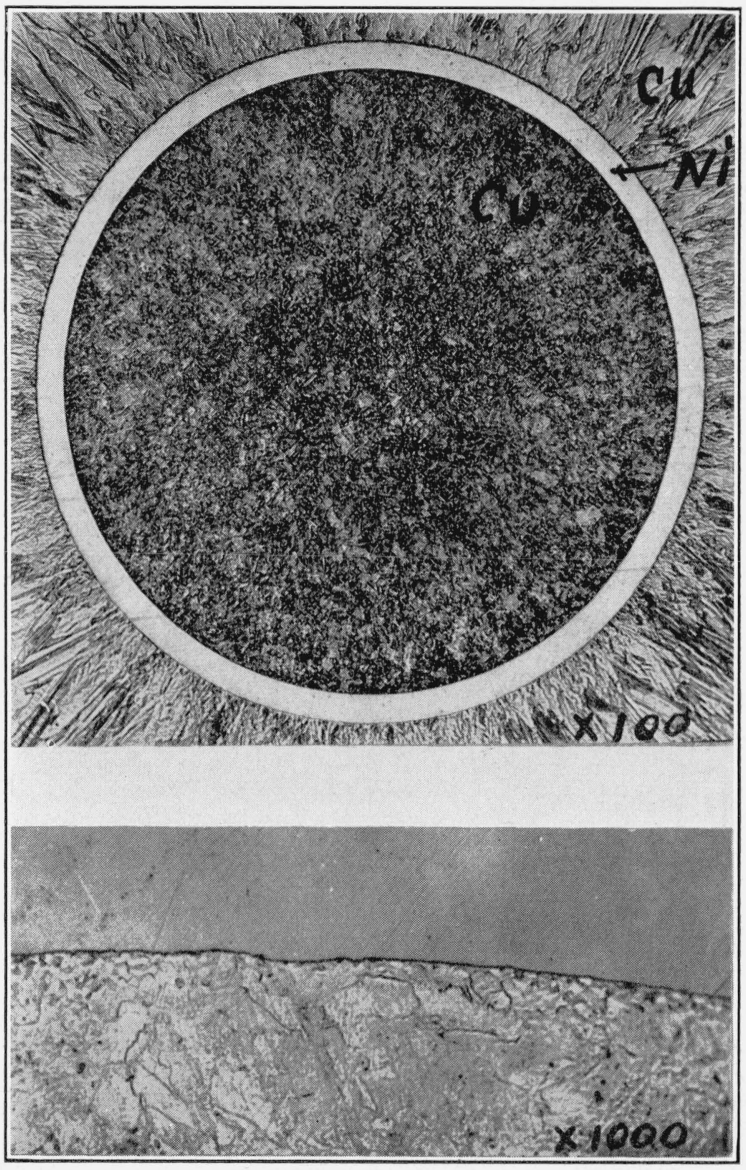

FIGURE 13.-Photomicrographs of a transverse cross section of the wire.

The wire was lightly nickel-plated, then heavily copper-plated. The photograph, with a magnification of $\times 1,000$, shows the most irregular portion of the cross section shown in the photograph with a magnification of $\times 100$. 
The \pm term shows the difference in inductance that would result from assuming either a natural or a uniform distribution of current in the cross section of the wire. If the current density were uniform over the cross section, the term would be negative; it would be positive if the current density varied inversely as the length of the helical filaments, the natural distribution.

\section{INDUCTANCE OF THE LEADS}

The inductance of the leads was computed by the formulas for the self and mutual inductance of straight wires and the formula for the

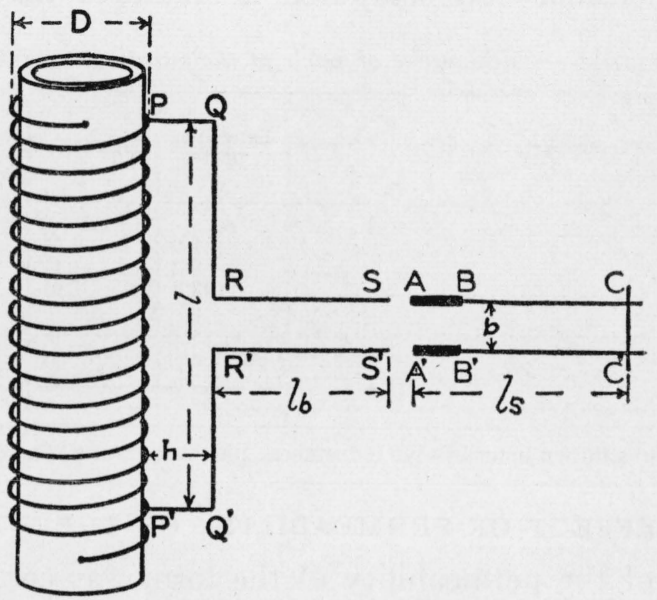

Figure 14.-Diagram of the helix with its leads and of the substitution inductor.

mutual inductance between the helix and a straight wire. ${ }^{10}$ The arrangement of the leads and the designations of the parts are shown in figure 14. The dimensions of the parts and the computed inductances are given in table 14.

TABLE 14.-Inductance of parts of the leads

\begin{tabular}{|c|c|c|c|c|c|}
\hline Symmetrical pairs of parts of the leads & $\begin{array}{l}\text { Length of } \\
\text { each part }\end{array}$ & $\begin{array}{c}\text { Diameter of } \\
\text { each part }\end{array}$ & $\begin{array}{l}\text { Self induct- } \\
\text { ance of each } \\
\text { part }\end{array}$ & $\begin{array}{c}\text { Mutual in- } \\
\text { ductance be- } \\
\text { tween the } \\
\text { parts of } \\
\text { symmetrical } \\
\text { pairs }\end{array}$ & $\begin{array}{l}\text { Mutual in- } \\
\text { ductance be- } \\
\text { tween pair } \\
\text { and solenoid }\end{array}$ \\
\hline $\begin{array}{l}P Q \text { and } P^{\prime} Q^{\prime} \\
Q R \text { and } Q^{\prime} R^{\prime} \\
R S \text { and } R^{\prime} S^{\prime}\end{array}$ & $\begin{array}{l}c m \\
\quad 1 \\
49.5 \\
37.5\end{array}$ & $\begin{array}{l}c m \\
0.0925 \\
.0977 \\
.0940\end{array}$ & $\begin{array}{r}m_{\mu h} \quad \\
6 \\
679 \\
497\end{array}$ & $\begin{array}{l}m_{\mu h} \\
<0.1 \\
+64 \\
-251\end{array}$ & 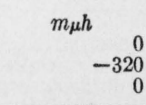 \\
\hline $\begin{array}{l}\text { Total inductance }=\text { twice sum of } \\
\text { each column }\end{array}$ & & & 2364 & -374 & -640 \\
\hline
\end{tabular}

Inductance of leads $=$ sum of all of the total inductances $=1350 \mathrm{~m} \mu \mathrm{h}$

10 These formulas are given on p. 21 of the previous publication. A typographical error consisting of a misplaced parenthesis occurs in one of the descriptions on this page. In the second line below eq 19, the expression should be $(l-b) / 2$. 


\section{INDUCTANCE OF THE SUBSTITUTION INDUCTOR}

The inductance of the substitution inductor was for the most part computed by the formulas for straight wires to which reference has already been made. In addition there is required the formula for the mutual inductance of two adjacent portions of a straight wire which are of unequal lengths. If the lengths of the two portions are $p$ and $q$ centimeters, the formula is

$$
M=(p+q) \ln (p+q)-p \ln p-q \ln q
$$

The parts of the substitution inductor, as designated in figure 14, have the dimensions and computed inductances that are given in table 15 .

TABLE 15.-Inductance of parts of the substitution inductor

\begin{tabular}{|c|c|c|c|c|}
\hline Part or parts & $\begin{array}{l}\text { Length of } \\
\text { part }\end{array}$ & Diameter & Self induct- & $\begin{array}{l}\text { Mutual } \\
\text { inductance } \\
\text { between } \\
\text { parts }\end{array}$ \\
\hline $\begin{array}{l}C C^{\prime} \\
B C+A^{\prime} A^{\prime} C^{\prime} \\
B C+\end{array}$ & $\begin{array}{r}c m \\
1.0 \\
2.2 \\
42.3\end{array}$ & $\begin{array}{c}\mathrm{cm} \\
0.06 \\
.1 \\
.01\end{array}$ & $\begin{array}{r}m \mu h \\
7 \\
33 \\
1522\end{array}$ & $\begin{array}{c}m \mu h \\
\end{array}$ \\
\hline $\begin{array}{l}A B \text { and } B C \\
A^{\prime} B^{\prime} \text { and } B^{\prime} C^{\prime} \\
A C \text { and } A^{\prime} C^{\prime}\end{array}$ & - no & (n) & 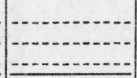 & $\begin{array}{r}9 \\
9 \\
-313 \\
\end{array}$ \\
\hline Total & - n & 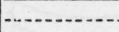 & 1562 & -295 \\
\hline
\end{tabular}

Inductance of substitution inductor $=$ self inductances, plus twice mutual inductances $=972 \mathrm{~m} \mu \mathrm{h}$

\section{EFFECT OF PERMEABILITY OF THE FORM}

The effect of the permeability of the form was computed by two different methods, as described in the previous paper. ${ }^{11}$ The necessary data for computing the effect and the results obtained are given in table 16 . The exact agreement by the two methods was not expected considering the assumptions involved. Neither of the methods is sufficiently general to take account of the portion of the form that extends beyond the winding used in the electrical measurements. If these extended portions were included, the correction would have a larger numerical value than that given in the table, but the amount would certainly be less than 1 part in a million.

TABLE 16.-Correction for the permeability of the form

[Constants and results]

\begin{tabular}{|c|c|c|}
\hline Quantity & Symbol & Value \\
\hline $\begin{array}{l}\text { Density } \\
\text { Mass susceptibility } \\
\text { Volume susceptibility=Do } \\
\text { Permeability } \\
\text { Outside diameter of form } \\
\text { Thickness of form } \\
\text { Length of form } \\
\text { Pitch of winding } \\
\text { Combumber turns. } \\
\text { (a) Integration method. } \\
\text { (b) Reluctance method. }\end{array}$ & $\begin{array}{l}D \\
\sigma \\
\kappa \\
=1+4 \pi \kappa \\
D_{0} \\
t \\
l \\
g \\
N \\
A L / L \\
\Delta L / L\end{array}$ & $\begin{array}{c}2.16 \mathrm{~g} / \mathrm{cc} \\
-0.42 \times 10^{-6} \\
-.90 \times 10^{-6} \\
.999989 \\
34.83 \mathrm{~cm} \\
6.58 \mathrm{~cm} \\
120 . \mathrm{cm} \\
.1 \mathrm{~cm} \\
1000 \\
-6.1 \mathrm{ppm} \\
-6.1 \mathrm{ppm}\end{array}$ \\
\hline
\end{tabular}

1 The mass susceptibility was measured by Dr. Posnjak of the Geophysical Laboratory of the Carnegie Institution of Washington. The value given is the mean for four samples, two from each end of the form.

11 See eq 23, p. 23 , and eq 33, p. 25 , of the previous publication. 


\section{COMPUTED INDUCTANCE DIFFERENCE}

The computed inductance difference is the inductance of the helix and its leads, $L$, minus that of the substitution inductor, $l$. The inductance of the helix must be corrected for the permeability of the form. From the preceding values

$$
L-l=103356307 \pm 91 m \mu h .
$$

The \pm 91 results from the uncertainty in the current distribution in the wire, which limits the accuracy that can be obtained in computing the inductance. In addition, there is an uncertainty resulting from possible errors in the values of the measured dimensions. The maximum presumptive error in each of the dimensions can be determined from the preceding data. The values of these errors and their effect on the computed inductance are given in table 17. The effect on the inductance was computed by formula 21 of the previous article. Computing the coefficients from the dimensions of the long glass inductor this equation is

$$
\frac{\delta L}{L}=1.74 \frac{\delta D^{\prime}}{D}-0.74 \frac{\delta l}{l}-0.0058 \frac{\delta d}{d} .
$$

TABLE 17.-Effect of presumptive errors on the computed inductance

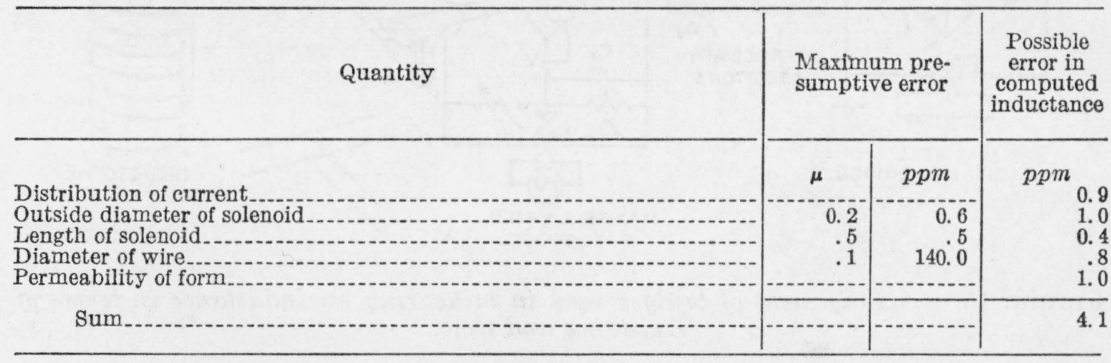

The maximum possible error as given in table 17 is 4.1 parts per million. Because it is improbable that the errors are all as large as indicated or that they all have the same sign, the error in the computed inductance is probably less than 4 parts per million.

\section{MEASUREMENT OF THE INDUCTANCE IN NBS INTERNATIONAL ELECTRICAL UNITS}

The inductance was measured in terms of the NBS international ohm and the mean solar second, giving the value in NBS international henrys. The experimental arrangement of apparatus is shown diagrammatically in figure 15 . The arrangement was the same, except for some minor details, as that described in the previous publication, and the procedure employed in making a determination was also the same. The alternating-current bridge was balanced first with the inductor connected in the bridge and then with the substitution inductor exchanged for it. The difference in the inductances was then obtained in terms of the fixed resistances of the bridge arms and of the difference in the capacitances used to measure the inductor and the substitution inductor. This procedure avoided the necessity 
of making corrections for the residual inductances of the bridge resistors and for the capacitance of the leads to the capacitors. The difference in the capacitances was then evaluated by the Maxwell capacitance bridge shown on the left, giving its value in terms of the resistances of the bridge arms and the rate of the vibrating contactor. Combining the results by the two bridges, the difference between the inductances of the inductor and the substitution inductor was obtained in NBS international henrys, because all resistances were stated in NBS international ohms and the rate of the vibrating contactor was known in mean solar seconds.

The two bridges were arranged so that they could be conveniently and rapidly operated, and so that the resistance of all resistors could be readily compared with standards obtained from the Resistance Section of this Bureau. The apparatus was in two adjoining rooms, each of which was heated electrically and continually maintained at

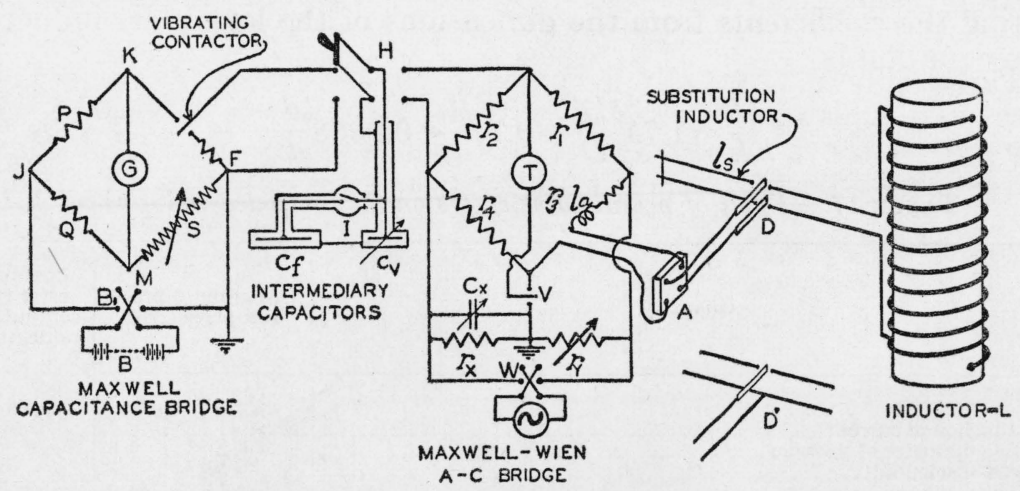

FigURE 15.-Arrangement of bridges used in measuring an inductance in terms of resistance and time.

The intermediary capacitors $C_{v}$ and $C_{f}$ can be connected to either bridge as desired by the switch, H. The inductor, $\mathrm{L}$, and the substitution inductor, $l_{s}$, were exchanged in the Maxwell-Wien bridge by the switch $D$ (or $D^{\prime}$ ). Part of the measuiements were made with the switch, as shown at $D$. The remainder were made with one blade of $D$ permanently connected to both $\mathrm{L}$ and $l_{s}$ as shown at $D^{\prime}$.

$25.2^{\circ} \pm 0.5^{\circ} \mathrm{C}$ as long as the outside temperature was sufficiently low. The air in both rooms was stirred by electric fans, but there was always some temperature gradient between the floor and ceiling, the amount depending on outside weather conditions. The fan for stirring the air in the inductor cabinet was about $1.5 \mathrm{~m}$ away from the inductor. The air was circulated to the inductor cabinet through two wooden pipes. Baffle plates in the cabinet distributed the air so thoroughly that the temperature difference between the bottom and top of the cabinet was normally as small as $0.2^{\circ} \mathrm{C}$.

\section{MAXWELL-WIEN ALTERNATING-CURRENT BRIDGE}

The Maxwell-Wien alternating-current bridge, shown at the right in figure 15, consisted of the inductor (or substitution inductor), the resistors, the air capacitor, and the detector. There were also special switches for exchanging the inductor and substitution inductor in the bridge and for reversing the current through them. Some changes 
were made in several of these parts after the previous description was published. In the following discussion, special emphasis will be given to the changes in the different parts with the exception of those made in the inductor which has already been described. The descriptions given in the previous paper of the auxiliary and substitution inductors, the detectors, and the alternating-current power supply need no modification.

Two sets of observations were required for a determination of the difference of the inductances corresponding to the two positions of the switch $D$. In one set the inductor was connected in the bridge; in the second set the substitution inductor. Each set consisted of four readings corresponding to the four combinations of positions of the two reversing switches $A$ and $W$. Before each reading the detector $T$ was connected to the Wagner ground and this arm balanced so that at the final balance of the main bridge the detector $T$ was at earth potential.

\section{(a) BRIDGE RESISTORS}

Three different types of resistors were constructed, each wound with bare manganin wire. The types were distinguished by the material of the form on which the wire was wound; viz, mica, glass, and quartz. The resistors of the mica type were wound on thin sheets of mica with serrated edges. The winding was unifilar and was not coated after winding. The resistors of the glass type were wound on tubes of Pyrex glass in the manner indicated in figure 12 of the preceding paper. The resistors of the quartz type were wound on tubes of fused quartz in the same manner as the glass type. All types had very small distributed capacitance. The inductance of each resistor of the mica type was about $15 \mu \mathrm{h}$; of those of the quartz and glass types about $60 \mu \mathrm{h}$.

The temperature coefficients of the resistors were negative and varied from 10 to 14 parts per million per degree centigrade. However, as the resistors were used in a bath at constant temperature, the temperature coefficients did not need to be known.

The load coefficient of a resistor is here used as the change in resistance (in parts per million) for a change of 1 watt in the heat dissipated in it. This change of resistance results from the temperature of the wire in the resistor being higher than that of the surrounding oil in which the temperature is measured. The load coefficient is directly proportional to the temperature coefficient, but is also influenced by other factors such as the viscosity of the oil and the rate of stirring.

\section{TABLE 18.-Load coefficients of resistors used in the Maxwell-Wien bridge}

[Each of the resistors had a nominal value of $650 \mathrm{ohms}$. Measurements were made with the resistors in the same oil and stirred at the same rate as when used in measuring inductance]

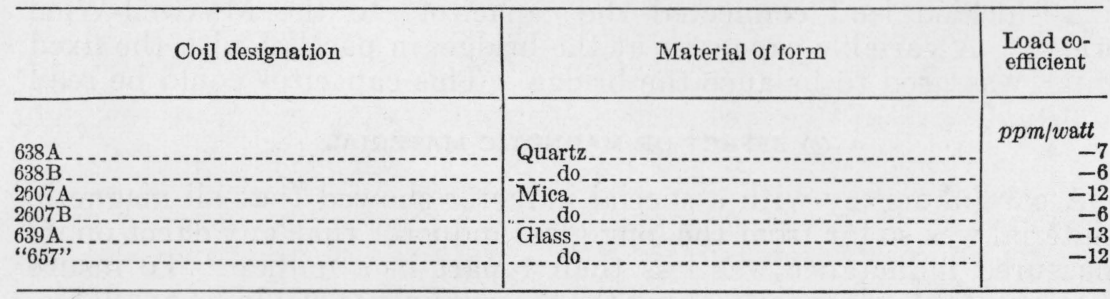


The load coefficients of some of the resistors used in the MaxwellWien bridge are given in table 18. These resistors were sometimes used in the alternating-current bridge with a load as high as 0.2 watt, while when compared with standards in the direct-current bridge the load was only 0.01 watt. Hence a correction of 1 or 2 parts per million in the measured resistance was required on account of the load coefficient. The load on other resistors used in the Maxwell-Wien bridge was so small that no correction was needed.

The different types of resistors had such different electrical constants that if any one or all had an alternating-current resistance that differed appreciably from its direct-current resistance, there would almost certainly be systematic differences in the measured inductance which could be correlated with the type of resistor. No such systematic difference was observed as can be seen from the data in table 19. In this table the values of inductance are given from determinations made on 4 successive days using the three different types of coils on each day. The maximum difference in the averages is only 3 parts per million, which is less than the experimental error at the time the measurements were made. Hence, the conclusion has been reached that with these types of resistors the resistance at $24 \mathrm{c} / \mathrm{s}$ is the same within limits of observation as for direct current.

TABLE 19.-Inductance of long glass inductor (NBS 1847) as measured by different types of coils in Maxwell-Wien bridge

Temperature: $26.1^{\circ} \mathrm{C}$

Frequency: $24 \mathrm{c} / \mathrm{s}$.

Capacitance: Measured with 100 charges and discharges per second in the Maxwell capacitance bridge.

\begin{tabular}{|c|c|c|c|}
\hline \multirow{2}{*}{ Date (1938) } & \multicolumn{3}{|c|}{ Measured inductance in NBS international microhenrys } \\
\hline & Quartz resistors & Glass resistors & Mica resistors \\
\hline $\begin{array}{l}\text { Apr. } 5 \\
\text { Apr. } 6 \\
\text { Apr. } 7 \\
\text { Apr. } 7 \\
\text { Apr. } 8\end{array}$ & $\begin{array}{r}103307.0 \\
8.1 \\
8.0 \\
6.9\end{array}$ & $\begin{array}{r}103307.4 \\
6.4 \\
7.9 \\
7.6 \\
7.0\end{array}$ & 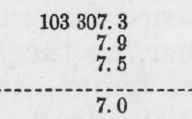 \\
\hline Average & $103307.5 \pm 0.5$ & $103307.3 \pm 0.5$ & $103307.4 \pm 0.3$ \\
\hline
\end{tabular}

(b) CAPACITORS

The capacitors were the same as those previously described; viz, 20 units each having a fixed capacitance of $0.01 \mu \mathrm{f}$ and two units each having $0.03 \mu$ f. One of the 0.01 units has been replaced by a bank of four units having fixed values of $0.005,0.002,0.002$, and $0.001 \mu f$, and a variable capacitor covering a range from 50 to $1500 \mu \mu \mathrm{f}$, any or all of which could be connected in parallel with the larger units. Any capacitance from about 100 to $260000 \mu \mu$ f could be obtained.

A shielded lead connected the capacitors to the Maxwell-Wien bridge. A variable capacitor at the bridge, in parallel with the fixed units, was used to balance the bridge. This capacitor could be read to $0.1 \mu \mu \mathrm{f}$.

\section{(c) EFFECT OF MAGNETIC MATERIAL}

A careful survey with a special inductor showed that all magnetic material was so far from the long glass inductor that any effect on its measured inductance was less than 1 part in a million. To insure that a suitable place for making the measurements would be available, 
the wooden floor of R214 East, referred to in the previous article, was replaced by a cement floor covered with linoleum. This removed the iron nails which had caused a slight uncertainty in the previous work. An exploration showed that the steel reinforcement in the ceiling was too far removed to produce a measurable effect on the inductance.

\section{(d) SPECIAL SWITCHES}

Two special switches were employed: one ( $A$, fig. 11$)$ for reversing the connections, to the bridge, of the inductor or of the substitution inductor; the other ( $D$ or $D^{\prime}$, fig. 11) for exchanging in the bridge the inductor for the substitution inductor, or vice versa.

A new switch was constructed to replace the one previously used at $A$, although the older one was employed during most of the measurements on account of its low resistance. The new switch was designed to insure that there would be no change in mutual inductance between the parts of the switch and the inductor when the switch was reversed. However, no measurable difference was observed when one switch replaced the other.

The switch for exchanging the inductors either had two blades, as shown at $D$ of figure 11, or a single blade, as shown in the insert at $D^{\prime}$. When both blades were used, only the inductor or the substitution inductor was connected to the bridge. When only one blade was used, one terminal of each inductor was permanently connected to the bridge. This latter arrangement modified the bridge readings because of the capacitance to earth of the solenoid.

\section{(e) CAPACITANCE TO EARTH OF THE SOLENOID}

The capacitance to earth ${ }^{12}$ of the solenoid was quite different from that of the substitution inductor. The original equations for the bridge assumed that this difference could be neglected, but a more complete study has shown that it must be given consideration. In order to simplify the treatment, the equations will be developed in which the capacitance to earth of both the solenoid and the substitution inductor are neglected and another capacitance to earth deliberately introduced into the inductance arm. A diagram of such a bridge is shown in figure 16. The capacitance to earth, $K$, is shown by dotted lines to be directly connected to the ground point of the third arm, though, in practice, there was no direct metallic connection because the walls of the room and other grounded objects formed the second plate of the ground capacitance.

The equation for computing the inductance, when measured by the bridge of figure 16 , is

$$
L^{\prime}=C^{\prime} r_{1} r_{4}-K r^{\prime}{ }_{3} r^{\prime \prime}{ }_{3}
$$

where $L^{\prime}$ is the inductance being measured and the meanings of the other symbols are given on the figure. Every set of measurements required the measurement of the difference of two inductances and hence two different bridge balances; one when the solenoid was in the bridge, the other when the substitution inductor was in the bridge. The resistances remained the same in the two balances since the resistance of the substitution inductor was adjusted to be equal

12 The importance of the capacitance to earth was first suspected because of a discrepancy in results when resistors of different magnitudes were used in the Maxwell-Wien bridge. The bridge equations to include the capacitance to earth were first developed by A. V. Astin, of this Bureau. 
to that of the solenoid. When $L$ was measured the capacitance of $C^{\prime}$ was designated as $C$, and when $l$ was measured, the capacitance of $C^{\prime}$ was given as $c$. The equations for the two balances, assuming a constant capacitance to earth, are

and

$$
L=C r_{1} r_{4}-K r_{3}^{\prime} r_{3}{ }_{3}
$$

Subtracting

$$
l=c r_{1} r_{4}-K r_{3}^{\prime} r_{3}^{\prime \prime} \text {. }
$$

$$
L-l=(C-c) r_{1} r_{4},
$$

so that the capacitance to earth does not influence the result if it is the same in both measurements. In order to test experimentally this conclusion, a capacitance to earth was obtained by attaching to the junction of $r^{\prime}{ }_{3}$ and $r^{\prime \prime}{ }_{3}$ a sheet of metal about 40 by $100 \mathrm{~cm}$ which was suspended by insulating threads near the center of the room. The values of both $C$ and $c$ were each increased about $3 \mu \mu \mathrm{f}$ by the addi-

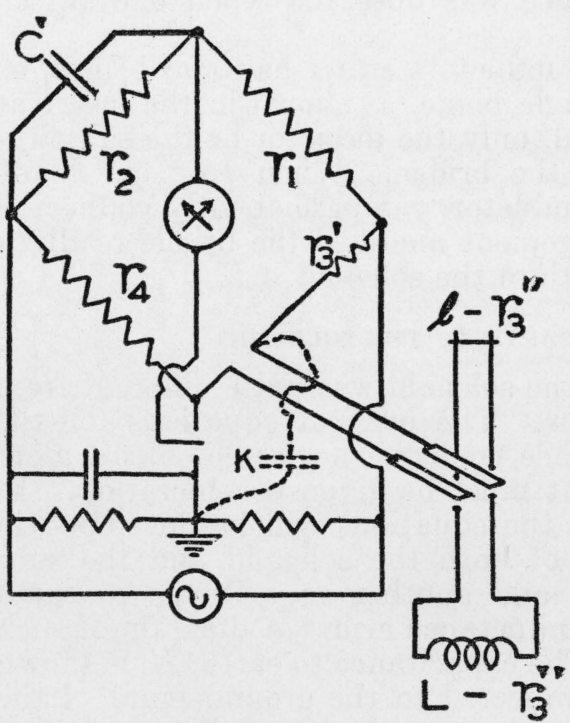

FIgURE 16.-Diagram of the Maxwell-Wien bridge with a Wagner ground showing a capacitance, $K$, from a point in one arm to the earth point. tion of this capacitance, but the value of $C-c$, and hence of $L-l$, was not measurably affected by its addition.

If the capacitance to earth is in any other arm, similar equations can be developed, and the effect on the difference in the inductances can be shown to be zero. This conclusion was also experimentally verified, using the sheet of metal described above and connecting it to various points along the $r_{2}$ arm. Although this capacitance caused marked changes in the values of $C$ and $c$, the difference between them for any position of the earth capacitance remained constant within experimental error.

The one condition under which the earth capacitance affects the value of $L-l$ is when this capacitance is changed between the two measurements.

When the solenoid is measured its capacitance is distributed along its length, whereas when the substitution inductor is measured the capacitance to earth is negligible unless the solenoid is connected to the bridge at one point. Hence the effect of the capacitance to earth of the solenoid produces a different effect in the two measurements of a set.

In order to obtain the effect of a capacitance to earth that was distributed along the solenoid the assumption was made that the effect on the Maxwell-Wien bridge equation of two or more capacitances to earth connected at different points was equal to the sum of the separate effects as they would be computed by eq 5 . Then the equation for the effect of an infinitesimal length of the solenoid at a distance 
$\alpha$ from the end was written, and this summed for all the infinitesimal lengths of the solenoid by integration from one end to the other. The resulting equation is

$$
L=C r_{1} r_{4}-K\left[\frac{r_{3}^{\prime} r^{\prime \prime}{ }_{3}}{2}+\frac{\left.\left(r^{\prime \prime}\right)_{3}\right)^{2}}{6}\right] .
$$

This differs from eq 5 in that the correction term consists of two parts. The first part has just half the value of the term in eq 5 . The second part depends only on the resistance of the solenoid and its capacitance to earth, and hence has a definite value for the solenoid regardless of the other constants of the bridge.

For the long glass inductor which had an earth capacitance of $43 \mu \mu \mathrm{f}$, a resistance of about $50 \mathrm{ohms}$, and an inductance of $0.1 \mathrm{~h}$, the term $K\left(r^{\prime \prime}{ }_{3}\right)^{2} / 6$ had a value which was less than 2 ten-millionths of the value of its inductance so that this term was negligible.

When the inductor was in the bridge, the balance was not affected by connecting to either of its ends one terminal of the substitution inductor. When the substitution inductor was in the bridge, the balance was the same when one terminal of the inductor was connected to the end of the substitution inductor next to the galvanometer as when the inductor was entirely disconnected, but was appreciably different if a terminal of the inductor was connected to the end of the substitution inductor which was farthest from the galvanometer terminal. If the latter connection is used, eq 5 must be employed to evaluate the inductance, but if the former connection is used the correction term is zero because $r^{\prime \prime}{ }_{3}$ is zero.

From the above considerations, two different procedures were developed for obtaining the value of $L-l$. In the first, the solenoid was entirely disconnected when measuring the substitution inductor. This necessitated the use of eq 9 for computing $L$. In the second, the coil was connected first to one end and then to the other of the substitution inductor, so that the average of the two readings obtained in this way gave the equation

$$
l=c r_{1} r_{4}-K r_{3}^{\prime} r^{\prime \prime}{ }_{3} / 2
$$

Subtracting this from eq 9 and neglecting the term $K\left(r^{\prime \prime}{ }_{3}\right)^{2} / 6$, the resulting equation is

$$
L-l=(C-c) r_{1} r_{4} .
$$

This equation is identical with the one used in the published work. However, in that work the procedure here outlined was not generally followed.

\section{MAXWELL CAPACITANCE BRIDGE}

Maxwell's bridge for the absolute measurement of capacitance was employed to measure, in terms of resistance and time, the capacitances that were used in the Maxwell-Wien alternating-current bridge. The Maxwell bridge was not fundamentally changed from that previously described, but a number of modifications were made. The inertia type of vibration commutator for charging and discharging the capacitors was used exclusively. Special galvanometers were constructed to supply experimental evidence concerning the accuracy of the integration of the current. The former bridge was replaced by a new bridge which was more convenient to operate. Additional calibrating resistances were employed and the resistance of the battery was studied. 
(a) THE VIBRATION COMMUTATORS

Three different vibration commutators of the inertia type were employed. These were attached to tuning forks having natural frequencies of approximately 100,400 , and $1000 \mathrm{c} / \mathrm{s}$. These forks were driven by alternating currents of exactly the frequencies listed above. These alternating currents were furnished by the Radio Section of this Bureau as submultiples of standard radio frequencies which were maintained with an accuracy of about 1 part in 10 million. Hence there was no uncertainty in the frequency of charge and discharge of the capacitors.

In measuring $0.1 \mu \mathrm{f}$ all three commutators were used, but when measuring $0.25 \mu \mathrm{f}$, only the 100 - and 400 -cycle forks were employed. There were two reasons for not using the commutator attached to the 1000 -cycle fork when measuring $0.25 \mu \mathrm{f}$. In the first place, the time of charge was so short that in order to have the capacitor completely charged the ratio arms of the bridge would have had to be reduced to $10 \mathrm{ohms}$ each, instead of $100 \mathrm{ohms}$, as used with the other commutator. With this reduced resistance all but one of the three available galvanometers were overdamped, so that their operation was slow and somewhat uncertain. In the second place, the internal resistance of the battery introduced so large an uncertainty in the computation of the correction factor that data made using this contactor would have been of little value. The effect of the battery resistance is discussed in greater detail in a later section.

The vibration commutator consisted of a tungsten reed which vibrated between platinum contacts. ${ }^{13}$ When the reed struck one of the contacts heat was produced and a thermal electromotive force might have been introduced into the circuit. In order to determine whether this electromotive force affected the measured capacitance, thermal electromotive forces were deliberately introduced first into the charging and then into the discharging circuit of the capacitor. In each circuit was a short length of constantan wire so that an appreciable electromotive force could be introduced by heating one end. These electromotive forces did not affect the measured capacitance when the readings were made with direct and reversed current, although they were, in every case, many times larger than those which may have been produced at the contacts.

\section{(b) THE GALVANOMETERS}

A galvanometer for use in a Maxwell bridge must have high ballistic sensitivity and low resistance. Its period must be long and its critical damping resistance less than the resistance of the bridge arms in parallel with it. Its zero must be stable, and it must correctly integrate the current flowing through it. In order to meet these requirements, the coil must have only a small number of turns of relatively large wire and must be in a strong magnetic field, the value of which is not appreciably changed by the large current through the coil when the capacitor is being charged. The permeability of the coil must be very nearly unity and the magnetic field must be very uniform in the region occupied by the coil.

Two new galvanometers were constructed and used in conjunction with one of those described in the earlier publication. The important

${ }^{18}$ See figure 16 of previous paper. 
constants of all three are given in table 20. The principal differences are in the materials of the magnets. In one, the magnets are compressed blocks of the oxides of iron and cobalt. ${ }^{14}$ In another, the magnets were cast Alnico, the trade name of a material which contains iron, aluminum, nickel, and cobalt, and which has very high retentivity. The third, which was the one used in the previous investigation, has a magnet made from cobalt magnet steel. The shapes of the different magnets are shown in figure 17 .
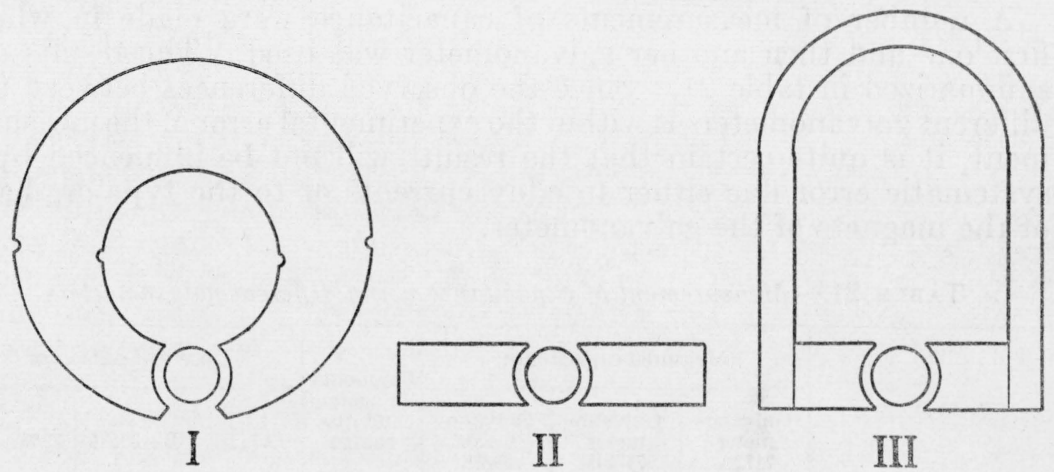

FIGURE 17.-Diagram showing the shapes of the magnets in the three galvanometers used in the Maxwell capacitance bridge.

Materials: I, Alnico; II, cobalt and iron oxides; and III, cobalt magnet steel.

Each shape was chosen because of the magnetic characteristics of the different materials. In every case the central core was of the same material as the magnet. Before magnetization iron spacers were placed between the magnet and the core in the expectation that, when they were removed after magnetization, the field would be nearly uniform over the region in which the coil was mounted.

TABLE 20.-Important constants of galvanometers used in the Maxwell capacitance bridge

\begin{tabular}{|c|c|c|c|c|}
\hline \multirow{2}{*}{ Constant } & \multirow{2}{*}{ Unit } & \multicolumn{3}{|c|}{ Galvanometer } \\
\hline & & $7172 \mathrm{~B}$ & $7172 \mathrm{~A}$ & 39538 \\
\hline Material of magnet.. & & Alnico.... & Iron and co- & Cobalt magnet \\
\hline Form of magnetic circuit.- & & Circle_.... & Bars.......... & Horseshoe. \\
\hline Height of coil & $\mathrm{mm} . .$. & & 64 & \\
\hline Width of coil & mm-... & $21 \ldots \ldots$ & $21-\ldots \ldots$. & 21. \\
\hline Diameter of wire in coil & mm........ & $0.2=\ldots \ldots$ & $0.2=\ldots-\ldots$ & 0.13. \\
\hline $\begin{array}{l}\text { Number of turns in coil } \\
\text { Resistance of coil and suspension st } 25^{\circ} \mathrm{C}\end{array}$ & Ohms.... & $29.5 \div \ldots$ & $38.5^{8}$ & $\begin{array}{l}24.5 . \\
5.07 .\end{array}$ \\
\hline Period & Seconds.... & 6 & 10 & 6. \\
\hline Critical damping resistance.................. & Ohms....... & $90 \ldots$ & $15 \ldots \ldots \ldots$ & 70. \\
\hline Current constant & $\left\{\frac{\text { Amperes }}{\text { mm }}\right.$ & $135 \times 10^{-10}$ & $125 \times 10^{-10}$ & $130 \times 10^{-10}$. \\
\hline Ballistic constant with critical damping.... & $\{$ Coulombs & $260 \times 10^{-10}$ & $770 \times 10^{-10}$ & $320 \times 10^{-10}$. \\
\hline & 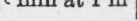 & & & \\
\hline
\end{tabular}

*stimated.

14 Described by C. S. Williams, Permanent magnet materials, Elec. Eng. 55, 19, (1936). He gives reference to the original Japanese article by Kato and Takel. 
The oxide material has a resistivity of more than $1000 \mathrm{ohm}-\mathrm{cm}$, while the Alnico and cobalt magnet steel materials have resistivities of less than $0.001 \mathrm{ohm}-\mathrm{cm}$. Hence, the conductivity of the oxide is less than 1 millionth of that of the others. Because the coil of a galvanometer used in a Maxwell bridge carries a variable current and is also in motion, there is a tendency for eddy currents to be produced in the nearby portions of the magnets. If these currents are sufficiently large they might affect the bridge setting, but they were certainly too small in the oxide magnet to produce a measurable effect.

A number of measurements of capacitance were made in which first one and then another galvanometer was used. The results are summarized in table 21. Since the observed differences between the different galvanometers is within the experimental error of the measurement, it is quite certain that the results will not be influenced by a systematic error due either to eddy currents or to the type or shape of the magnets of the galvanometer.

TABLE 21.-Measurement of capacitance using different galvanometers

\begin{tabular}{|c|c|c|c|c|c|c|c|}
\hline \multirow[b]{2}{*}{ Date (1938) } & \multicolumn{3}{|c|}{ Measured capacitance } & \multirow{2}{*}{$\begin{array}{c}\text { Frequency } \\
\text { of charge } \\
\text { and dis- } \\
\text { charge }\end{array}$} & \multicolumn{3}{|c|}{ Observed difference } \\
\hline & $\begin{array}{c}\text { Galvano- } \\
\text { meter } \\
7172 \mathrm{~A}\end{array}$ & $\begin{array}{l}\text { Galvano- } \\
\text { meter } \\
7172 \mathrm{~B}\end{array}$ & $\begin{array}{c}\text { Galvano- } \\
\text { meter } \\
39538\end{array}$ & & $(A-B)$ & $(B-39538)$ & $(39538-\mathrm{A})$ \\
\hline Feb. 25 & $\begin{array}{c}\mu \mu f \\
245212.6\end{array}$ & $\stackrel{\mu \mu f}{245} 214.1$ & $\begin{array}{c}\mu \mu f \\
245212.1\end{array}$ & $c / s$ & $\stackrel{p p m}{-6}$ & $\stackrel{p p m_{+8}}{ }$ & ${ }^{p p m} m_{-2}$ \\
\hline Jan. 6.... & & $\left\{\begin{array}{l}245 \\
245209.2 \\
242.7\end{array}\right.$ & $\begin{array}{l}245211.2 \\
245 \quad 212.4\end{array}$ & $\begin{array}{l}100 \\
400\end{array}$ & 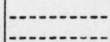 & $\begin{array}{r}-8 \\
+1\end{array}$ & $-\ldots$ \\
\hline Mar. 3.. & $\left\{\begin{array}{l}245234.8 \\
245232.3\end{array}\right.$ & $\begin{array}{r}245 \text { 231. } 5 \\
245 \text { 231. } 5\end{array}$ & 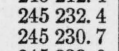 & $\begin{array}{l}400 \\
400\end{array}$ & $\begin{array}{r}+13 \\
+3\end{array}$ & $\begin{array}{l}-4 \\
+4\end{array}$ & $\begin{array}{l}-10 \\
-6\end{array}$ \\
\hline & & $\begin{array}{l}245231.9 \\
245215.9\end{array}$ & $\begin{array}{l}245232.0 \\
245214.4\end{array}$ & $\begin{array}{l}400 \\
100\end{array}$ & $-\ldots+\ldots$ & $\begin{array}{r}0 \\
+6\end{array}$ & $\mid-\ldots+n$ \\
\hline Mar. 4.... & & $\left\{\begin{array}{l}245215.9 \\
245212.7\end{array}\right.$ & $\begin{array}{l}245214.4 \\
245212.2\end{array}$ & $\begin{array}{l}100 \\
400\end{array}$ & (-n) & $\begin{array}{l}+6 \\
+2\end{array}$ & $-1-1,-1$ \\
\hline Mar. $7 \ldots$ & - & 245211.3 & 245212.5 & 400 & & -5 & 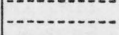 \\
\hline
\end{tabular}

(c) THE BRIDGE

The new bridge was assembled in a single box which contained the ratio coils, the rheostat arm, and the switches for reversing the battery connections and for closing the galvonometer circuit. Each ratio arm had resistances of 10, 100, 1000, and $10000 \mathrm{ohms}$. The rheostat arm had 8 dials in which the steps were $0.01,0.1,1,10,100$, 1000, 10000 and $100000 \mathrm{ohms}$. The resistances differed from their nominal values by only a few parts in 10 thousand.

\section{(d) THE CALIBRATING RESISTORS}

Six different calibrating resistors were used to determine the correction to the reading of the bridge in the absolute measurement of capacitance. Each calibrating resistor consisted of a number of coils, each having the same nominal value, which were so connected to terminal blocks or switches that they could be connected either in series or in parallel. Because the resistance of each coil differed from its nominal value by less than 0.1 percent, the resistance of all the coils in series differed by less than 1 part in a million from the product obtained by multiplying the resistance of all the coils in parallel by the square of the number of coils. However, in the parallel connection the connecting resistances produced a different effect from that 
in the series connection, necessitating a correction to the simple rule given in the preceding sentence. In two of the resistors this correction was less than 1 part in a million. In two others, the correction was made zero by arranging the connections so that, to the series arrangement, there was added a small compensating resistance which was not connected in the parallel arrangement. In two others, corrections had to be applied when making the computations. The constants of each resistor and the amount of the correction term are given in table 22 .

TABLE 22.-Constants of the calibrating resistors for the Maxwell capacitance bridge

\begin{tabular}{|c|c|c|c|c|c|c|c|}
\hline \multirow[b]{2}{*}{ Resistor } & \multirow{2}{*}{$\begin{array}{l}\text { Number } \\
\text { of coils } \\
\text { in resis- } \\
\text { tor, } n\end{array}$} & \multicolumn{3}{|c|}{ Nominal resistance } & \multicolumn{2}{|c|}{$\begin{array}{l}\text { Maxwell bridge char- } \\
\text { acteristics }\end{array}$} & \multirow{2}{*}{$\begin{array}{l}\text { Correc- } \\
\text { tion } \\
\text { term, } \beta \mathbf{a}\end{array}$} \\
\hline & & $\begin{array}{l}\text { Each } \\
\text { coil }\end{array}$ & $\begin{array}{l}\text { Coils in } \\
\text { series, } \\
\quad R_{z}\end{array}$ & $\begin{array}{l}\text { Coils in } \\
\text { parallel, } \\
R_{p}\end{array}$ & $\begin{array}{c}\text { Capaci- } \\
\text { tance }\end{array}$ & $\begin{array}{l}\text { Number of } \\
\text { charges } \\
\text { and dis- } \\
\text { charges } \\
\text { per second }\end{array}$ & \\
\hline $\begin{array}{l}\text { NBS } 40109 \\
\text { NBS } 1917 \\
\text { NBS } 955 \\
\text { NBS } 8859\end{array}$ & $\begin{array}{l}10 \\
10 \\
10 \\
10\end{array}$ & $\begin{array}{l}\text { Ohm } \\
10000 \\
10000 \\
10000 \\
10000\end{array}$ & $\begin{array}{l}\text { Ohm } \\
100000 \\
100000 \\
100000 \\
100000\end{array}$ & $\begin{array}{r}\text { Ohm } \\
1000 \\
1000 \\
1000 \\
1000\end{array}$ & $\begin{array}{r}\mu f \\
0.1 \\
.1 \\
.1 \\
.1\end{array}$ & $\begin{array}{l}c / s \\
100 \\
100 \\
100 \\
100\end{array}$ & $\begin{array}{r}p p m \\
0 \\
0 \\
0 \\
-8\end{array}$ \\
\hline NBS 8859 & $\begin{array}{l}5 \\
5\end{array}$ & 10000 & 25000 & b 1000 & .1 & 400 & -8 \\
\hline $\begin{array}{l}\text { NBS } 8859 \\
\text { NBS } 35231 \ldots \\
\text { NBS } 1920 \ldots\end{array}$ & $\begin{array}{r}5 \\
20 \\
10\end{array}$ & $\begin{array}{r}10000 \\
2000 \\
1000\end{array}$ & $\begin{array}{l}50000 \\
40000 \\
10000\end{array}$ & $\begin{array}{r}2000 \\
100 \\
100\end{array}$ & $\begin{array}{l}.2 \\
.25 \\
.25\end{array}$ & $\begin{array}{l}100 \\
100 \\
400\end{array}$ & $\begin{array}{r}-8 \\
0 \\
-2\end{array}$ \\
\hline
\end{tabular}

- The correction term, $\beta$, is taken from the equation $R_{a}=n^{2} R_{p}\left(1-\beta \times 10^{-6}\right)$, where $R_{a}$ is the series resistance, $R_{p}$ is the resistance in parallel, and $n$ is the number of coils. Both the $R_{a}$ and $R_{p}$ are the resistances from the same terminals, which, in every case, were amalgamated copper studs designed to fit into mercury cups.

b In addition to measuring the resistance of the 10 coils in parallel, a measurement is required of the difference in the resistances of the 2 halves of 5 coils each when connected in series.

The resistance of each resistor, when the coils were in parallel, was either 100 or 1000 ohms. The resistance of each was compared, within a few minutes of the time it was used to calibrate the Maxwell bridge, with the resistance of each of a group of standard resistors which were furnished and certified by the Resistance Section of this Bureau. These standard resistors were kept in an oil bath which was at room temperature of about $25^{\circ} \mathrm{C}$. The relative values of their resistances were determined whenever measurements of inductance were made and they were frequently sent to the Resistance Section for recalibration.

The calibrating resistors were so chosen that, when connected in series and used to replace the capacitor and commutator in the absolute capacitance bridge, the balancing of the bridge could be accomplished by a change in the rheostat arm of less than 2 percent of its value when measuring the capacitance. Since the coils of the bridge were not adjusted with an accuracy of 0.01 percent, the calibration errors of the 1,000-ohm coils had to be considered when computing the capacitance from the bridge readings. In no case did this correction exceed 1 part in a million. The coils of the bridge were sufficiently stable, so that no uncertainty resulted from this correction. 


\section{(e) THE RESISTANCE OF THE BATTERY}

The resistance of the battery arm may conveniently be considered in two parts; viz, the metallic leads from the bridge to the battery terminals and the internal resistance of the battery. The resistance of the leads is a definite quantity that can be readily measured, but the internal resistance of the battery is indefinite since it depends on the method of measurement, the amount of current drawn from the battery at the moment and, for a storage battery, its condition of charge. Hence it is important to select a battery with a low internal resistance in order that the uncertainty in this resistance may be small.

In the previous paper it was shown that an uncertainty, $\delta B$, in the battery resistance, introduced an uncertainty, $\delta F$, in the correction factor. The relation is given by the equation

$$
\delta F=n C \delta B,
$$

where $n$ is the number of charges and discharges per second and $C$ is the value of the capacitance being measured. But since $\delta C / C=\delta F / F$, and since $F$ is very nearly unity, the effect of an uncertainty $\delta B$ in the battery resistance can be computed from the equation

$$
\frac{\delta C}{C}=n C \delta B
$$

In order to show the effect of an uncertainty in $B$ in the measured capacitance, table 23 has been prepared to give the effect of an error of $0.1 \mathrm{ohm}$ in $B$ on the measured value for each capacitance and each frequency used in this investigation.

TABLE 23.-Effect of an error of $0.1 \mathrm{ohm}$ in the battery resistance on the measured capacitance

\begin{tabular}{|r|r|r|}
\hline Capacitance & \multicolumn{2}{|c|}{ Error in capacitance } \\
\cline { 2 - 3 } & $\begin{array}{c}\text { At 100 charges } \\
\text { and discharges } \\
\text { per second }\end{array}$ & $\begin{array}{c}\text { At 400 charges } \\
\text { and discharges } \\
\text { per second }\end{array}$ \\
\hline uf & $p p m$ & $p p m$ \\
0.1 & 1 & 4 \\
.2 & 2 & 8 \\
.25 & 2.5 & 10 \\
\hline
\end{tabular}

The resistance of the battery was determined by measuring its drop in potential when a known current was drawn from it. Although several batteries were used at different times, a particular one (designated E30+G30) was usually employed. The measured resistance of this battery was $0.15 \mathrm{ohm}$, with an uncertainty of about $0.05 \mathrm{ohm}$. A confirmation of this value was obtained in measurements of a capacitance of 0.25 microfarad, using 100 and 400 charges and discharges per second. In one series of 12 measurements, in which the capacitance of $0.25 \mu f$ was measured on each occasion, using both 100 and 400 charges and discharges per second, the average value at 
100 charges and discharges per second was 5 parts per million less than the average value at 400 charges and discharges per second. If this difference was caused by an error in the battery resistance a value $0.085 \mathrm{ohm}$ instead of $0.15 \mathrm{ohm}$ would have reduced the difference to zero. In all the reduction of data, the measured battery resistance of $0.15 \mathrm{ohm}$ has been used.

\title{
VII. OBSERVATIONAL DATA AND RESULTS OF THE ELECTRICAL MEASUREMENTS
}

The electrical measurements were made between January 14 and June 25, 1938. The results are summarized in table 24 .

\section{TABLE 24.-Difference between the inductances of the long glass inductor (NBS 1847) and the substitution inductor}

\begin{abstract}
Measurements made during the first 6 months of 1938 .
Temperature of inductor: $26.1^{\circ} \pm 0.5^{\circ} \mathrm{C}$.

Frequency used in the alternating-current bridge: $24 \mathrm{c} / \mathrm{s}$.

Frequency used in the capacitance bridge: 100 charges and discharges per second.
\end{abstract}

[The individual values from which this summary is made are plotted in figure 18]

\begin{tabular}{|c|c|c|c|c|c|c|}
\hline \multicolumn{4}{|c|}{$\begin{array}{c}\text { Nominal values of constents in } \\
\text { Maxwell-Wien bridge }\end{array}$} & \multirow{3}{*}{$\begin{array}{c}\text { Mean } \\
\text { value of } \\
\text { inductance } \\
L-l\end{array}$} & \multirow{3}{*}{$\begin{array}{l}\text { Number } \\
\text { of obser- } \\
\text { vations } \\
\text { in group }\end{array}$} & \multirow{3}{*}{$\begin{array}{c}\text { Average } \\
\text { deviation } \\
\text { of indi- } \\
\text { vidual de- } \\
\text { termina- } \\
\text { tion from } \\
\text { mean of } \\
\text { group }\end{array}$} \\
\hline \multirow{2}{*}{$\begin{array}{l}\text { Capaci- } \\
\text { tance, } C\end{array}$} & \multicolumn{3}{|c|}{ Resistances } & & & \\
\hline & $r_{4}$ & $r_{1}$ & $r_{2}$ & & & \\
\hline$\mu f$ & Ohms & Ohms & Ohms & NBSint. $\mu h$ & & $\mu h$ \\
\hline 0.1 & 1300 & 800 & $\left\{\begin{array}{l}1300 \\
1950\end{array}\right.$ & $\begin{array}{r}103306.6 \\
6.2\end{array}$ & $\begin{array}{r}15 \\
1\end{array}$ & \pm 0.67 \\
\hline & 1625 & 325 & 1950 & 6.0 & 1 & \\
\hline 2 & 975 & 525 & 975 & 6.1 & 1 & \\
\hline .2 & $\begin{array}{l}525 \\
325\end{array}$ & $\begin{array}{r}975 \\
1625\end{array}$ & $\begin{array}{l}525 \\
380\end{array}$ & $\begin{array}{l}5.7 \\
7.0\end{array}$ & $\begin{array}{l}1 \\
1\end{array}$ & - \\
\hline .25 & 1300 & 325 & $\begin{array}{r}650 \\
1300 \\
2600\end{array}$ & $\begin{array}{l}6.7 \\
7.0 \\
6.4\end{array}$ & $\begin{array}{r}1 \\
26 \\
3\end{array}$ & .52 \\
\hline & & & 650 & 7.0 & 33 & .61 \\
\hline .25 & 650 & 650 & $\begin{array}{l}1300 \\
2600\end{array}$ & $\begin{array}{l}6.8 \\
6.6\end{array}$ & $\begin{array}{l}1 \\
4\end{array}$ & \\
\hline .25 & 325 & 1300 & 325 & 6.5 & 2 & .10 \\
\hline & & & & & 90 & \\
\hline
\end{tabular}

Mean of the 90 observations: $103306.8 \mu \mathrm{h}$

A verage deviation of the 90 individual values from the mean: $\pm 0.59 \mu \mathrm{h}$. Maximum deviation of any value from the mean: $1.5 \mu \mathrm{h}$.

All of the individual results are plotted in chronological order in figure 18. There were 90 sets of data, no one of which contained any known error. The average value of the difference between the inductance of the inductor and that of the substitution inductor was

$$
103306.8 \mu \mathrm{h} \text {. }
$$

The average variation from the mean was $\pm 0.59 \mu \mathrm{h}$ and the maximum variation was $1.5 \mu \mathrm{h}$.

The results are summarized so that all the values obtained with any given arrangement of the constants in the alternating-current bridge are grouped together. There are three large groups, the smallest of 


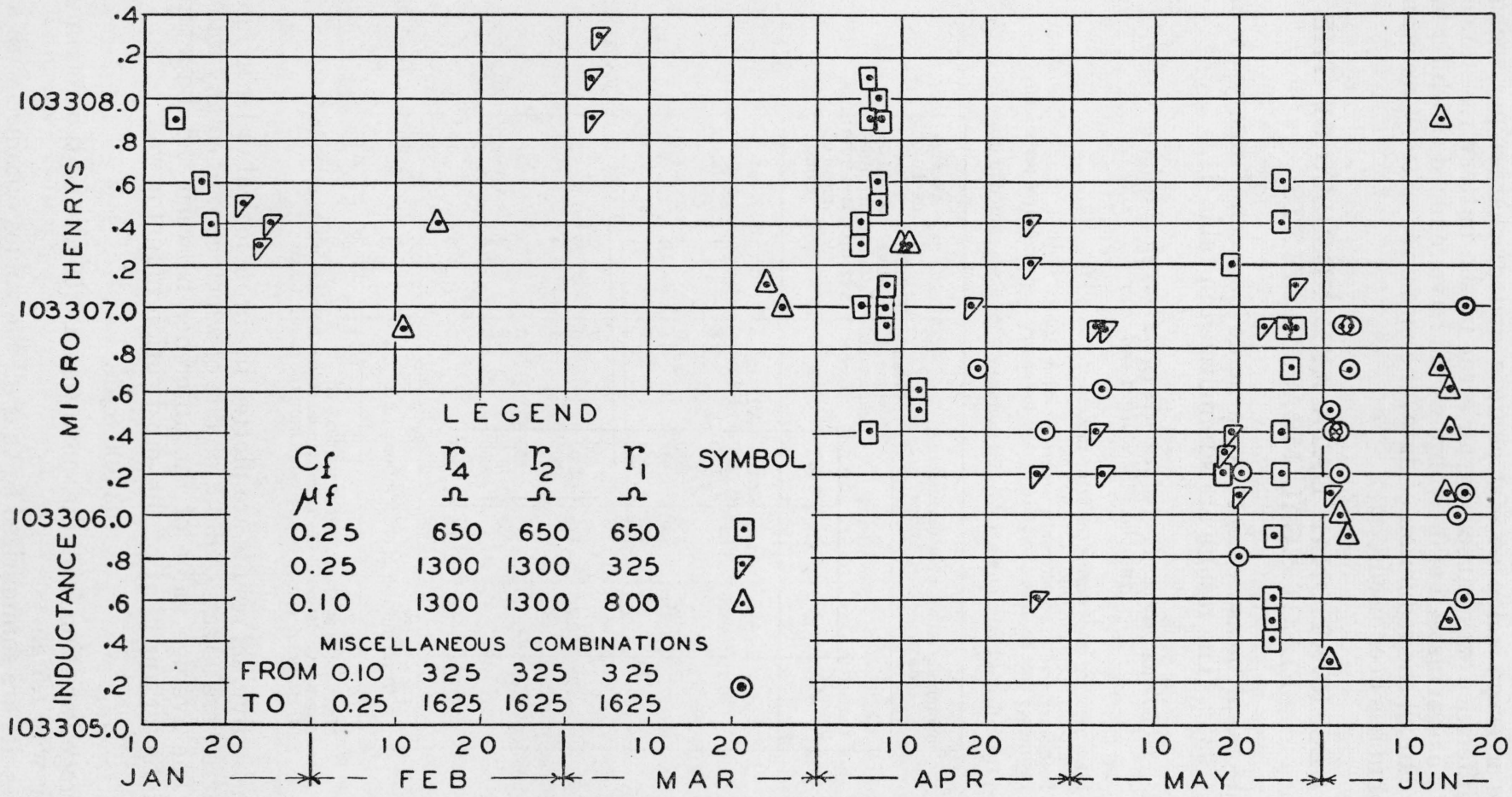

FIGURE 18.-Values of the measured inductance on different days

By means of the symbols given in the legend there are shown the different combinations of resistances and capacitance used in the alternating-current bridge. (See fig. 15.) 
the three having 15 sets of observations. In no case does the average for any one of these large groups differ from the average of all the observations by more than $0.2 \mu \mathrm{h}$, or 2 parts in 1 million. As the errors of observation may account for this difference, there is no indication that the value obtained for the inductance was dependent on the magnitudes of the resistances and capacitances which were used in this bridge. This conclusion is further supported by the results for the 10 small groups of 1 to 4 observations, since in every case the difference from the mean is less than the errors of observation.

The results as plotted in figure 18 appear to indicate a decrease in inductance with time. There seems to have been a greater variation in the results in May and June than in January, February, and March. These anomalies could have resulted either from errors in the electrical measurements, from a gradual change in the dimensions of the inductor, or from a drift in any one of the units on which the electrical measurements were based.

The most probable causes of errors in the electrical measurements were changes in the room temperature and humidity. They were more nearly constant when the rooms were heated during the winter months than after the artificial heating was discontinued about May 1. However, observations were never made when the room temperature was above $27^{\circ} \mathrm{C}$ or the relative humidity above 60 percent. Experience has indicated that these conditions are not sufficiently different from those in a heated room to appreciably affect the results. Moreover a study of the data has shown no correlation between the measured inductance and either room temperature or room humidity. Hence, there is no evident reason why the electrical measurements should have caused the apparent change in inductance.

The dimensions of the inductor that might have changed sufficiently to affect its inductance are its length and diameter. Both of these would have been changed if the copper wire, which was under tension when wound on the form, should have gradually elongated. Such an elongation would have increased the diameter of the helix and decreased its length. Both these changes would have increased the inductance, whereas the observed change was in the opposite direction. Hence the apparent drift in inductance cannot result from the release in tension of the copper wire. On the other hand, if there is a plastic flow in the glass form on which the helix is wound there would be a decrease in inductance. While a flow of this nature occurs in some kinds of glass, the Pyrex glass used in this form is very permanent, being the same kind as is used in the largest telescope mirrors. The probability of such a flow is very small. This question can be definitely settled by new measurements of the diameter, which will be made in the near future.

There are two units to which all of the electrical measurements are referred; viz, the unit of time and the unit of resistance. The unit of time is the mean solar second. This depended primarily on the astronomical observations which are regularly made at the United States Naval Observatory. The crystal clocks, which served as the standards of time during this research, were daily compared with the clocks of that observatory. The drift, if any, in the time unit was much too small to affect the measured inductance.

The unit of resistance was the NBS international ohm, as maintained by the Resistance Section of this Bureau. Its stability is $94848-38-4$ 
shown by the relative constancy of resistors made from different materials and of those having widely different values. If there are any changes with time, they are of quite a different order of magnitude from those required to explain the discrepancies indicated in this investigation.

The above discussion has not indicated the probable cause of the apparent change of the inductance of the long glass inductor with time. Probably there is some undiscovered change in some feature of the electrical measurements, such as a change in the resistance of the battery used in the absolute measurement of capacitance. A detailed study of all features of the electrical measurements is planned.

\section{THE RESULT}

The result of this determination with the long glass inductor was obtained by dividing the difference, between the computed inductance of the solenoid and the substitution inductor in absolute henrys, by the difference in their measured inductances in NBS international henrys. The computed difference in the inductances, as given on page 407 , was

$$
L-l=103356.3 \text { absolute microhenrys. }
$$

The measured difference in their inductances, as given in table 24, was 103306.8 NBS international microhenrys.

The ratio of these two values is 1.000479 . Hence the result of this determination may be stated as

$$
1 \text { NBS international ohm }=1.000479 \text { absolute ohms. }
$$

The authors are of the opinion that this does not differ from the true value by as much as 20 parts in a million.

\section{WEIGHTED RESULT OF THIS AND THE PREVIOUS INVESTIGATION}

The results of the previous investigation are in error because the capacitance to earth of the inductors was not considered. Hence some estimates have been made of the magnitudes of the corrections that should be applied to the different inductors. By assuming that each had a capacitance to earth of $35 \mu \mu$, the correction was computed for several combinations of resistances that were used in measuring the inductance in the Maxwell-Wien bridge. The smallest computed correction was $2 \mathrm{ppm}$, the largest $7 \mathrm{ppm}$. The application to all the different observations would be laborious and did not seem to be justified. It seemed sufficient to increase by $5 \mathrm{ppm}$ the value of the ratio determined for each inductor, as given in table 24 on page 81 of the previous paper.

The mechanical dimensions of the long glass inductor were so much more uniform and were measured with so much greater accuracy than was the case with the inductors previously measured that results obtained with it apparently should be given a greater weight in averaging results. On the other hand, the accuracy of the electrical measurements has not been appreciably increased except as regards the capacitance to earth of an inductor for which corrections can be applied to the previous results. Hence in averaging the results of both investigations, the value of the ratio obtained in this investiga- 
tion, using the long glass inductor, has been given twice the weight of that obtained when measuring the quartz inductor, which was the best of the three used in the previous investigation. The results, their assigned weights, and the weighted mean are given in table 25 .

TABLE 25.-Values of the ratio of the absolute ohm to the NBS international ohm, as obtained from the inductors used in this and the preceding investigation, together with the weights assigned to them

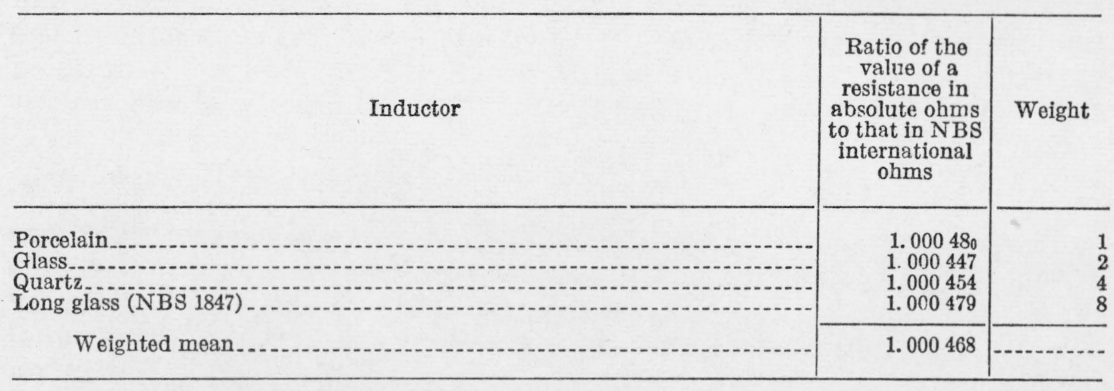

The most probable value from the results of the two investigations can be stated as

\section{NBS international $\mathrm{ohm}=1.000468$ absolute ohms.}

The NBS international ohm is, according to the 1937 comparison by the International Bureau of Weights and Measures of the units of the national laboratories, 3.7 parts per million less than the mean international $\mathrm{ohm}$. Using this relation,

\section{1 mean international ohm $=1.000472$ absolute ohms.}

Additional observations which will be completed before the end of this year may slightly alter this value.

\section{RESULTS RECENTLY OBTAINED IN OTHER LABORA- TORIES}

Since the publication of our previous paper, the following results of investigations in other laboratories have been published.

\begin{tabular}{|c|c|c|c|}
\hline Laboratory & Method & $\begin{array}{l}\text { Ratio of } \\
\text { the abso- } \\
\text { lute to the } \\
\text { interna- } \\
\text { tional ohm }\end{array}$ & $\begin{array}{c}\text { Possible error as estimated } \\
\text { by investigator }\end{array}$ \\
\hline $\begin{array}{l}\text { National Physical Laboratory } \\
\text { Laboratoire Central d'Electricite. }\end{array}$ & $\left\{\begin{array}{l}\text { Lorenz }{ }^{1} \\
\text { Campbell }^{2} \\
\text { Picard }^{3}-\ldots . .\end{array}\right.$ & $\begin{array}{l}1.00050 \\
1.000500 \\
1.00052\end{array}$ & $\begin{array}{l}\text { 30. } \quad p p m \\
35 . \\
\text { Several units in last signif- } \\
\text { cant figure. }\end{array}$ \\
\hline
\end{tabular}

1 Vigoureux, Nat. Phys. Lab. Collected Researches, 24, 277 (1938).

2 Hartshorn and Astbury, Phil. Trans. A 236, 423 (1937).

3 Jouaust, Picard, and Herou, Bul. soc. franç. electr. [5] 8586 (1938).

The authors acknowledge the help received from many of their associates at the National Bureau of Standards, only a few of whom have been specifically mentioned in this paper.

Washington, July 23, 1938. 